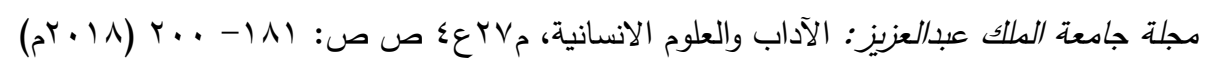

DOI:10.4197/Art.27-4.7

\title{
سيميائيَّة الغياب في ديوان "ما تلاه عليّ الغياب" دراسة في ضوء سيميائيَّة الأهواء
}

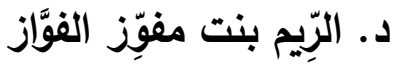 \\ أستاذ الأدب الحديث المساعد بقسم اللغة العربية وآدابها \\ جامعة جلة - المعلكة العربية السعودية
}

مستخلص. ينطلق المنهج السيميائي من فرضية أن النّص يحتوي على بنية ظاهرة وبنية عميقة، وتحليلهما يقوم

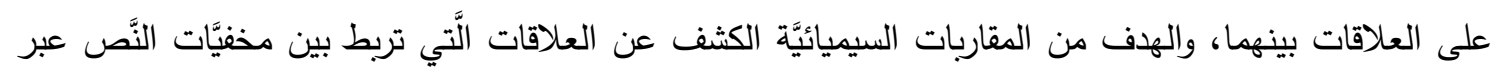

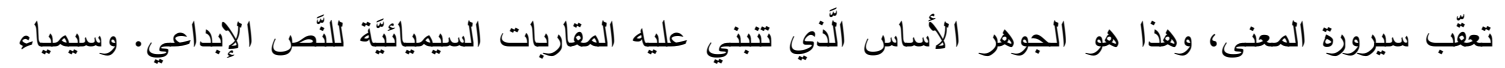

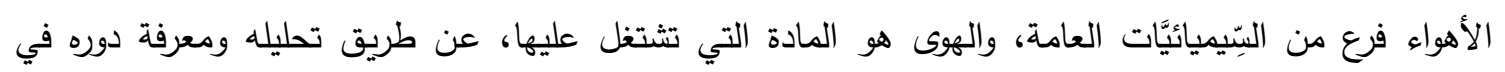

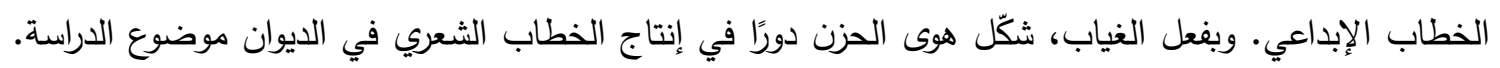
فقد استدعت الذَّات الثاعرة عددًا من صور هوى الحزن المتمثل في غياب ذوات أو مواقف معينة؛ بوصفه سابقًا على التمظهرات الدلالية، وفاعلاً في إنتاجها.

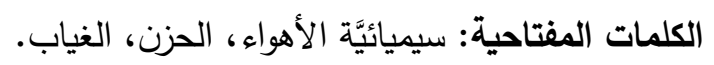

الغياب" للشاعر السعودي ماهر مهل الرحيلي'، من

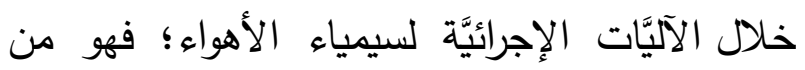
أنجح المناهج الحديثة لدراسة النص الإبداعي من أجل فهم اشتغال العواطفَّ في الخطاب، والبحث عن الكيفية والآلية التي تشكل بها الحزن، وكفاية الذَّات منه، وصولًا إلى تجلي آثاره في الخطاب.

r شاعر من المدينة المنورة، و أستاذ في الأدب العربي في الجامعة

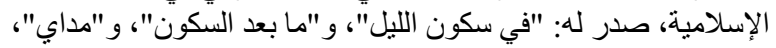

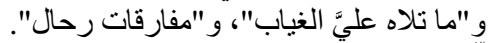

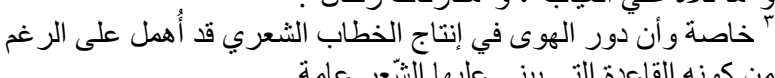

\section{مدخل}

سيمياء الأهواء تكثف عن مختلف الدلالات التي تحملها الأهواء المعبّر عنها، وعن اشتغالاتها وكيفية بناء المعنى من خلال الأهواء، ولذا سيتبع البحث الإجراءات التي اقترحها كل من "جاك فونتاني" و"أ.ج.غريماس" في كتابهما "سيميائيات الأهواء"' وعليه؛ وقع اختياري على ديوان "ما تلاه عليَّ passions.SEUIL.PARIS.France.1991. 
"الفينومينولوجيا" تدخل إلى حقل دراستها في فترة الثمانينات، إذ بدأت السيميائيَّة تحوّل اهتمامها عن الملفوظ الخطابي وتوجهه إلى "المقام التلفظي" على إثر تبنيها لمنظور (l'instance énonciative) "الخطاب بالفعل" (le discours en acte) الذي ينظر إلى الخطاب على أنه عملية إنتاج، وعلى أنه ملفوظ في طور التلفظ.' وبهذا أصبحت السيميائيَّة تمحور اهتمامها حول "فعل التلفظ" و "العمليات التلفظية" المنتجة للدلالة.

وخلال العقود الأخيرة، جعلت السيميائيَّة أهمية لمعنى الأهواء أو العواطف (موضوع سيميائيَّة الأهواء)؛ فالعامل إلى جانب أنه يعمل، فهو يشعر ويحتاج إلى الى الحالتين معًا لإثبات وجوده والتعبير عن مشاعره والتأثير في الآخرين؛ لذا فسيميائيَّة الأهواء تحاول أن تعزز مكانتها داخل النظرية السيميائيَّة العامة، للتدليل على استقلالية البعد الانفعالي على المستوى النظري والتطبيقي على حد سواء، ويعرف هذا النوع من السِّيميائيَّات بأسماء أخرى على نحو: السيميائيَّة

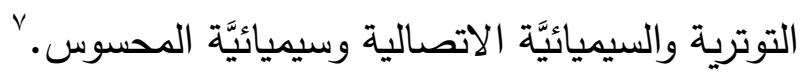

\section{سيمياء الأهواء}

يعد الهوى جزعًا من كينونة الإنسان وأحكامه وميوله وتصنيفاته. وهو المادة الأساس في سيمياء الأهواء، باعتبار الهوى سابقًا على الدلالات المستترة، فهو من

.Courtés.J, Analyse sémiotique du discours; de ${ }^{7}$ l'énoncé a l'énonciation, Hachette, Paris , 1991, p.247

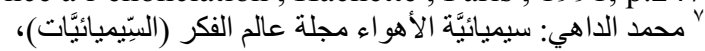

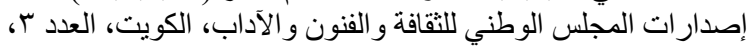

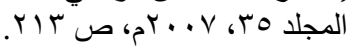

وقد وقع الاختيار على ديوان "ما تلاه عليّ الغياب" لما يتميز به من عمق وغموض واعٍ، كما يشكّل الديوان كتلةً عاطفية حزينة بفعل الغياب؛ فالغياب يسيطر على كل أجزاء الخطاب الشعري فيه. وهو ما يعني أن هنالك هوئً تأثرت به الذَّات، حتى أصبح عندها كفاية ذاتية لإنتاج هذا الخطاب الحزين. السيمياء العامة وسيمياء الأهواء استقرت السيميائيَّة منذ نشأتها في أواخر الخمسينات على "الخطاب" موضوعًا لبحثها، وجعلت البحث عن المعنى مادة مشروعها العلمي وموضوعه أيضا، وفي الستينات ظل البحث في الأبعاد التلفظية الفعلية مستبعدا من ميدان الدرس السيميائي؛ لعدم اتفاقه مع مبدأ البنيوية، الذي أرست عليه السيميائيَّة نظريتها. ومن المعلوم أن سيميائيَّة السبعينات خضعت لوجهة النظر التي ترى في الخطاب "ملفوظا" تامًا ومنتهيًا، وظلت وفية لمنطق (العمل)(l'action) التحويلي المستند على مفهوم "التمفصل" (l'articulation) الإبستيمولوجي، ضمن إدراك متقطع للعالم، لا يمسك بالمعنى إلا في تجزئه وتشظيه، وفي كنف الإلف السيميائيَّة البنيوية جعلت "السردية" مبدأَها أساسًا لتحليل الخطاب الملفوظ دون أن تتناول الجزء التلفظي منه. وبقيت كذلك إلى أن بدأت آثار موجة

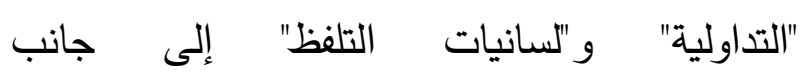

كورتيس جوزيف: مدخل إلى السيميائيَّة السردية و الخطابية، ت. د. د.

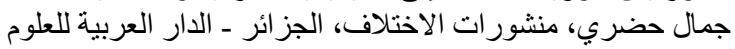

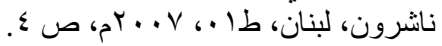
Greimas.A.J - Fantanille. J, Sémiotique des passions ; Des états de choses aux états d'âme, Paris, Seuil, 1991, p. 08 . 
والعواطف الإنسانية في السيميائيات قد أعاد للذات اعتبارها بعدما تم استبعادها عند البنيوية، لذا لابد من إعادة تشكيل النموذج التوليدي، لأن التشكلات الهووية تتموقع في ملتقى كل محافل المسار التوليدي للدلالة، فتمظهرها يقتضي بعض الثروط القبلية الخاصة ذات الطبيعة الإبستيمولوجية، وكذلك

$$
\text { بعض عمليات التلفظ". ' }
$$

تهتم سيميائيَّة الأهواء بالحالة النفسية أو الذَّات الانفعالية في علاقتها بالموضوع أو الأشياء، ويقوم التحليل السيميائي للأهواء من تصييخ الحالات بناء على الكفاءات التي تحدد الذَّات والموضوع، ودور الهوى في العلاقة بينهما، وهو ما يعني الانطلاق من

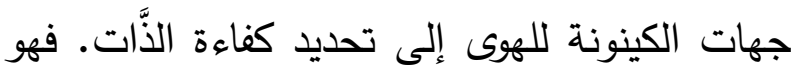

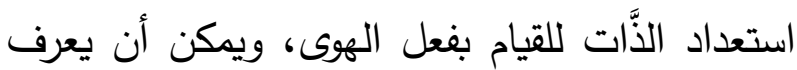

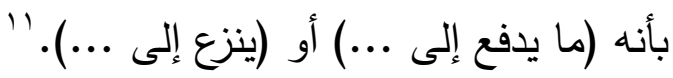

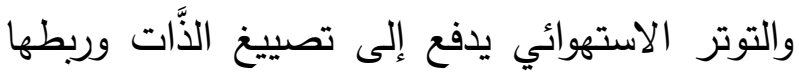
بالموضوع. فالتوتر يوّلد الاستهواء، والاستهواء يولد الداء

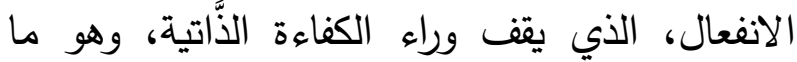
ينتج عنه عناصر عاملية، أو فعل تلفظي خطابي. كما هو موضح في الثكل الآتي:

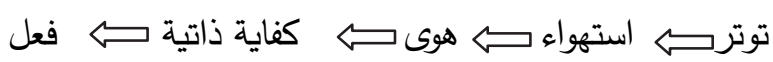
وعليه، فسيميائيَّة الأهواء تتحقق في تحفي تحديد كفاءات الذَّات وتحديد التوترات، إذ "تعين التوترية الاستهوائية

' محمد بادي: سيميائيات مدرسة باريس، المكاسب و المشاريع (مقارنة

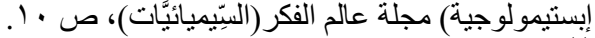

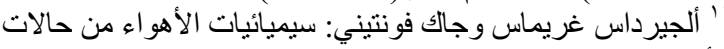

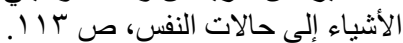

حيث الطبيعة وممكنات الترّكيب يعدّ "سلسلة من الحالات الانفعالية التي تتطوّر خارج البُعدين

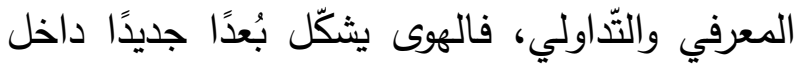

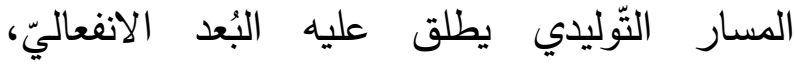
فالإنسان لا يفعل فقط، بل يُضمّن الفعل شحنة انفعاليّة تحدّد درجة الكثافة التي يتحقق من خلالها

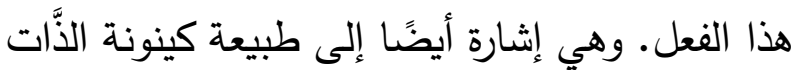

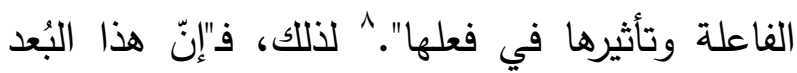
يتجسّد في مرحلة أولى من حيث التحققات الخطابيّة

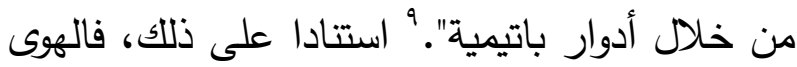
يحاول تقليص الفجوة بين المعرفة والحس، فدراسة الأهواء لا تهذف إلى التعرف على العلامات التي لتهن على الأهواء؛ وإنما تهتم بآثارها المعنوية كما تتشكل

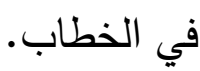
وعليه اهتمت سيميائيَّة الأهواء بالجانب الشعوري والنفسي لعامل الذَّات أثناء عملية الإنجاز والانتقال من الوضعية البدئية إلى الوضعية النهائية. فإذا لهاء كانت سيميائيَّة العمل تهتم بفعل التحول، فإن إنى سيميائَّة الأهواء تركز على الحالات لعامل الذَّات في الملفوظ السردي. وبذللك، "فسيميائيَّة الأهواء تندرج في سياق المشروع النقدي الذَّاتي للنظرية

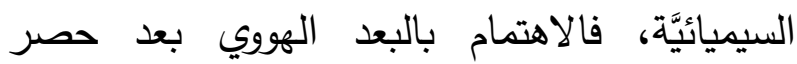

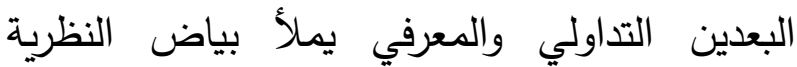
السيميائيَّة الأساس، إن ظهور إثكالية الأهواء

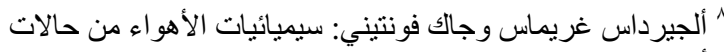

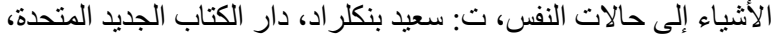

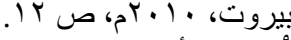
9 تتعلق الأدوار الباتيمية بالحب و الغيرة والغضب. 
يصوّر المربع السيميائي حالتين متضادتين؛ الغياب

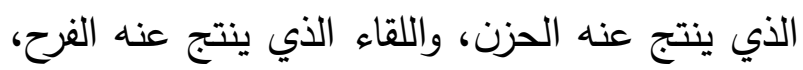

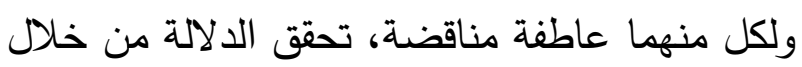
العلاقات القائمة بين التضاد، وفق برنامج استهوائي.

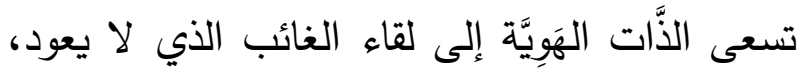

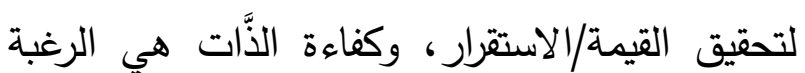
إلى جانب الإرادة مستتدة على العاطفة، فالحب

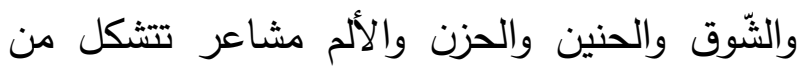
العاطفة، تعتبر زيادة مقابلة مع البنية التّي تمثّل

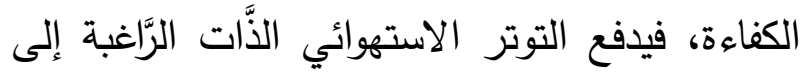

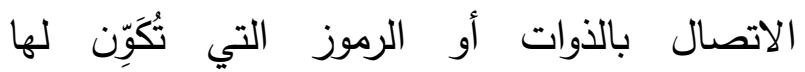
القيمة/الاستقرار ؛ من أجل التخلص من التوتر الناجم

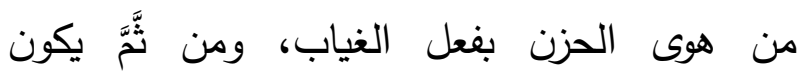
لاستدعاء هذه الرموز دور فاعل في تصوير هوى لهي

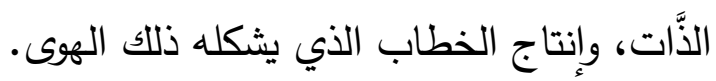
وسيشير البحث للذات الهَوِيَّة التي ترغب في تحقيق

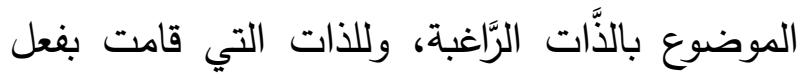

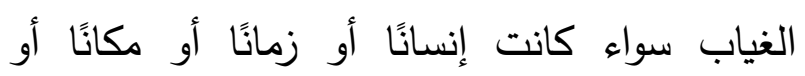
مشاعر بالذَّات الغائبة. تشكلات الهوى في الديوان تشكل ثنائية الحضور والغياب معظم الآثار الأهوائية حسب غريماس؛ فبين الحضور المغيب والغياب المستحضر تكمن تشكيلات الهوى في الديوان على لهئ
مجموع الثروط القبلية للدلالة". ك' ويعتمد التحليل في سيميائيَّة الأهواء على المعيار القيمي، ومدى هيمنة الهوى على النص أو الخطاب، وتأثيره في إنتاجه.

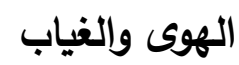
ارتبط الغياب بمشاعر الحزن، فالحزن نقيض الفرح وهو خلاف السرور با"، ويكون لفقد عزيز أو خوفًا من فقده، ويعظم هذا الأمر ويزداد إلى توقع حدوث

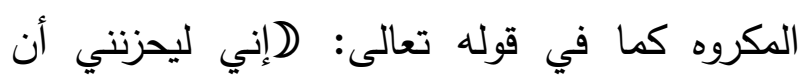
تذهبوا به ه.

ويتجلى الغياب بوصفه هوى فاعلًا في إنتاج المعنى في قصائد ديوان "ما تلاه عليَّ الغياب"، متخذا من هن بندي الحزن والقلق والخوف من الفقد حالة استهوائية شكلت الخطاب الشعري بصبغة حزينة. وعليه،

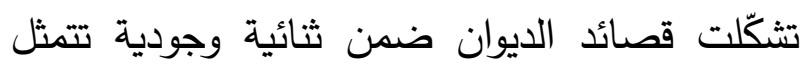
في الغياب الذي يقابله اللقاء والضياع الذي يقابله الاستقرار، ويمكن أن نمثل لهذه الثنائية بالثكل

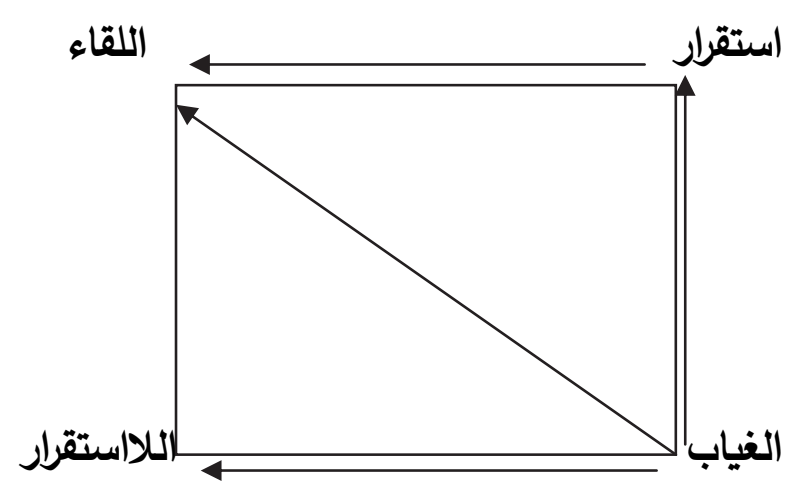

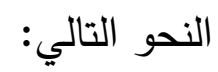


خفْق الحنين يضخّ من شريانه خوف الليالي من

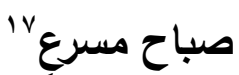

وطغيان هوى الحنين يكثف عن الحالة الثعورية

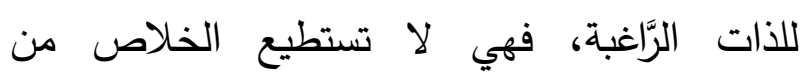
الذكريات المتعلقة بالذَّات الغائبة، ويتجلى ذلك في للكي البيتين التاليين: دثرّت قلبي.. حين حنت أضلعي بيديّ.. لكن ثم بعض زوايا أنا حينها ينساب فيها الثــوق دون تردد

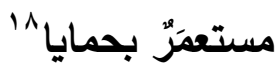
يبرز على المستوى السطحي للخطاب الشعري تشاكل الغياب المضاد لتشاكل اللقاء، وهو ما يسهم في تجلي هوى الحنين، حيث يصعد فضاء الحنين

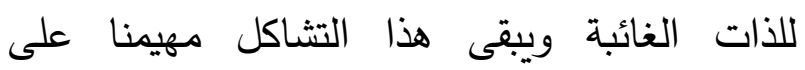
الخطاب الشعري: - (الثمان أي شوقٍ يلم مني حطامي أو ينقي من الحنين عظامي؟! 19

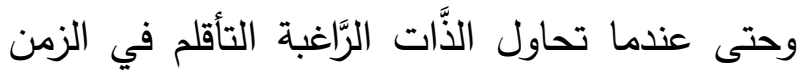

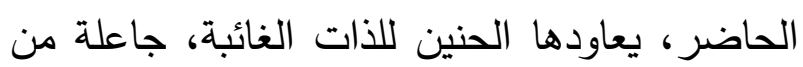
هذا الحنين قوتها: والأنملات تغني رعشة لمست فونها

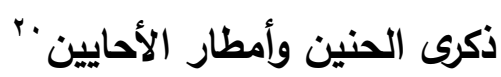
نلاحظ أن هوى الحنين طغى على الخطاب الشعري

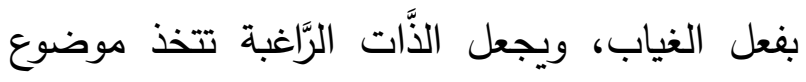

الحنين

بين الحضور والغياب يكمن الحنين من جهة، والأمل

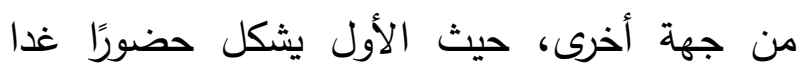

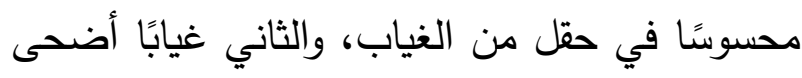

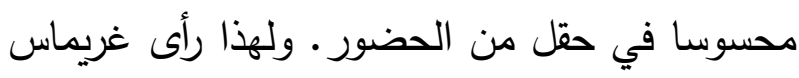
أن الانتظار والحنين أكبر عاطفتين تشكلان سيمياء الأهواء. الأن الناء يتكون هوى الحنين في الخطاب على شكل توتر بين

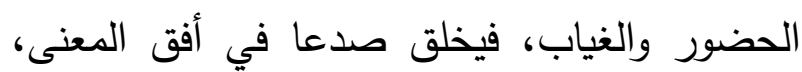

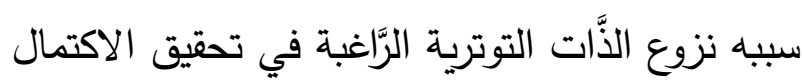
رغم حضور الخيبة. ويتقاطع الحنين مع هوى الحزن

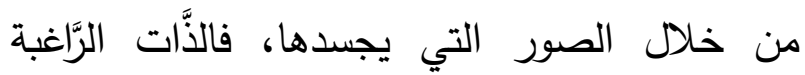
تجمع بين صور الذَّات الغائبة وذكرياتها بشحنة الحنين في قصائد الديوان، ففي فالذاكرة تصر على ودربن

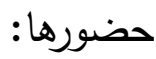
ما أسرع الزمن الملحَّ يعيد ذكراها يظن القلب أصبح ناسيا! 17 نجد أنَّ هوى الحنين مصاحب لغياب الذَّات الغائبة،

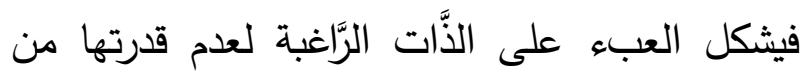

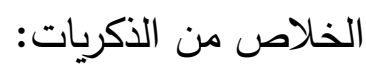

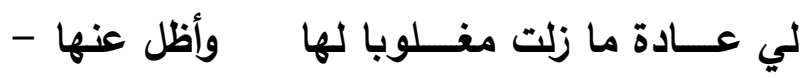
راضيًا- لم أقلِع

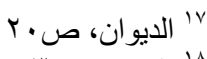

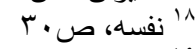

$$
\begin{aligned}
& 19 \text { '19 نفسهة، ص صل }
\end{aligned}
$$

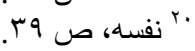

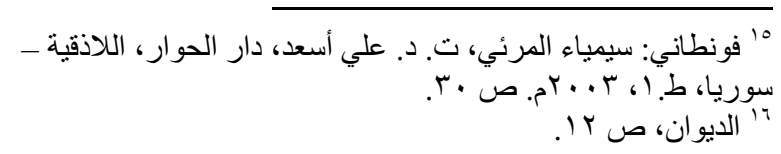


الأسئلة" بعد المرور على اليأس من تحقيق القيمة

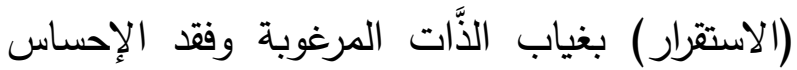
بالذَّات الممثل للقيمة المعوضة لقيمة الاستقرار . ويتبدى اليأس على مستوى الخطاب الثعري من خلال سيطرة الألفاظ الدالة، دلالة على انقطاع صيرورة لم تبلغ غايتها. لذلك فهي تمثل الإشارة الخطابية السطحية لتوفر شروط اختفاء القيمة للذات الرَّاغبة، و وتترجم على المستوى الإبستيمولوجي

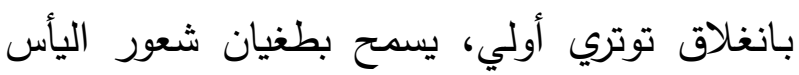

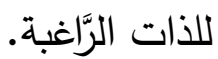

\section{ما زلت تبحث عن جثامين المنى}

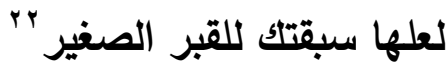

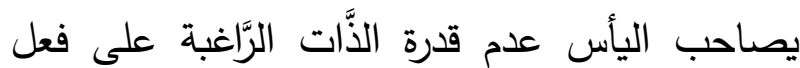
شيء حيال فعل الغياب، فالذَّات تملك الإرادة ولكن مع عدم القدرة على الفعل لاستحالة تحقيق القيمة،

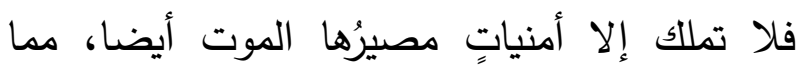
يجعل الذَّات الرَّاغبة متأزمة لا تملك الحل، فتئخذ من

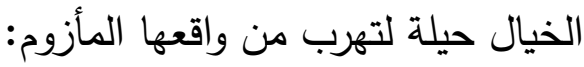
يراودني الهروب لألتقيك هناك في شمل الأماني الباقية لا شيء أملكه

سوى هذا الخيال ويرتبط بهوى اليأس القلق، فالذَّات القلقة حائرة

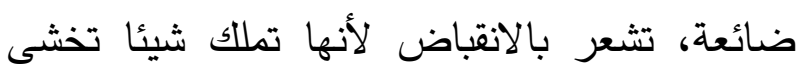
عليه الفقدان، ويصل هوى اليأس في أعلى درجاته
اللقاء بالذَّات الغائبة أفقا معنويا يغطي وجوده الإضماري على الوجود الفعلي للواقع، جاعلة من لإلياء

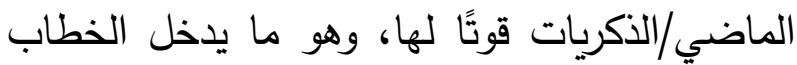
الثعري في حركة دورانية تعود به دوما إلى الزمن

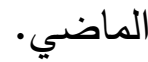

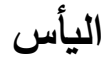
يعد اليأس هوى سلبيا، يقوم على خلفية الحرمان من

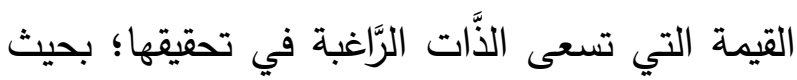
يتبع هذا الحرمان خيبة، وينشأ اليأس خطابيا نتيجة اتحاد عالمين متعارضين؛ فالذَّات الراغية يتخذ اليأس لايها جهتين مستقلتين عن بعضهما، تتعلق إحداهما بالإخفاق والحرمان فيما تتصل الأخرى بالثقة والانتظار . فاليأس يقع في نقطة تتجاذبه فيها قوى تتراوح بين الواجب والإرادة والقدرة والمعرفة، إلا أن

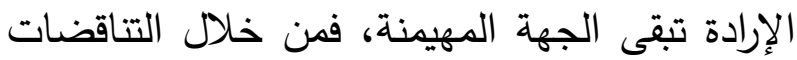
الداخلية للذات، يحدث شق داخلي في الذَّات سببه وعي الاستحالة الذي يطبع إرادة الذَّات اليائسة.

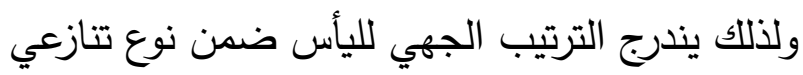
تتأرجح فيه الكفة بين إرادة الكينونة من جهة، ومعرفة

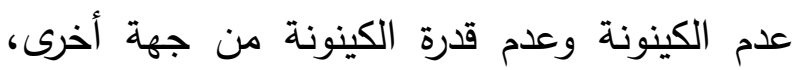

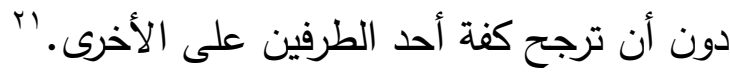

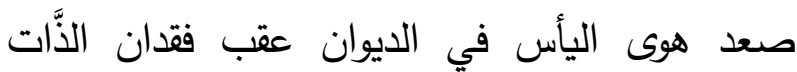

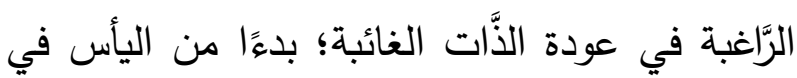

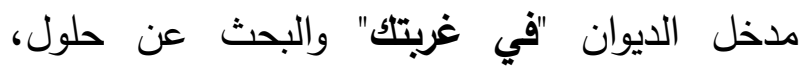
وصولا إلى القصيدة التي ختم بها الديوان "فتيل 
عند الذَّات الرَّاغبة مع وقوع فعل الموت، لأنها ل ل الذَّات الخائفة من المستقبل:

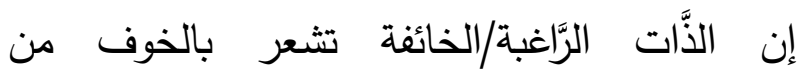
تستطيع فعل أي شيء حياله: المستقبل، فيحضر هوى الخوف من المستقبل،

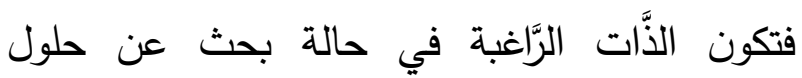
أعطاك العمر!

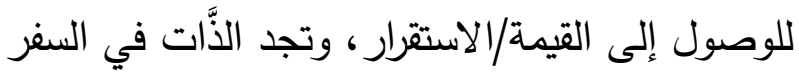
الخوف

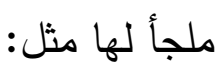

أأتوق للأسفار؟!... ما لي لم أجد

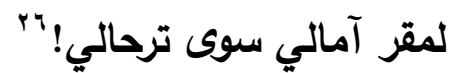

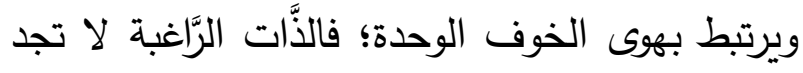

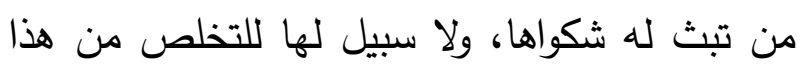
الشعور إلا فعل الكتابة: لا صوت يهمس لي في وحلتي.. نهمّ

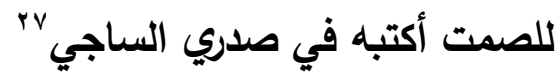
الأَّات الخائفة من ضياع الهَوِيَّة: بفعل شعور الخوف المتسبب بفعل غياب الذَّات الذّات

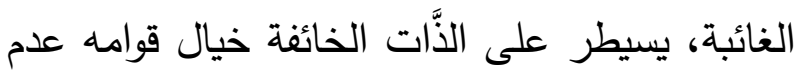
قدرة الفعل، فهي لا تستطيع حتى التعبير عن لهني مشاعرها، مما يجعلها تشعر بضعفها وقلة حيلتها: يقيني أن الحبر قليل..

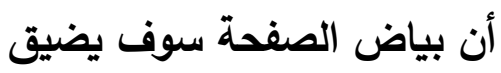

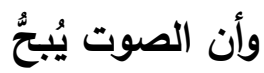

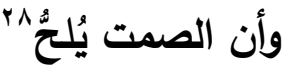
وهذا الضعف الذي تشعر به يجعلها في خوف من فقد هويتها، فيسيطر عليها هوى الخوف مما يجعله
تعاني الذَّات الخائفة صراعًا بين اعتقاد الكينونة مع واجب الكينونة مما يولد هوى الخوف؛ حيث إن

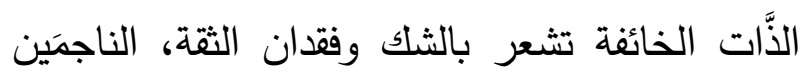

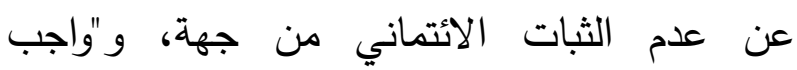
الكينونة" الذي تترجمه صور الترقب والانتظار المنوطة بالخطر من جهة أخرى؛ نظرا لأن هذا

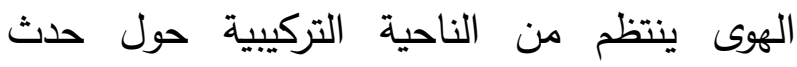
استشرافي ذي سمة انقباضية يجعل الذَّات الخائفة تستحضر ما هو غائب وتكابده وتخشى الفقدان.

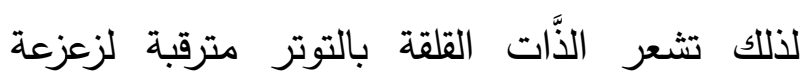

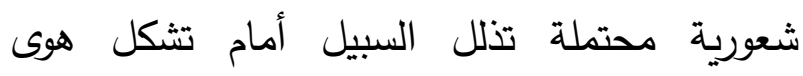
الخوف، وتفضي إلى استقطاب نهائي نحو الانشراح أو الانقباض. تتذبذب الذَّات القلقة في الديوان بين هذين القطبين

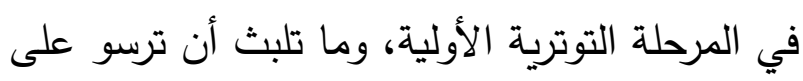

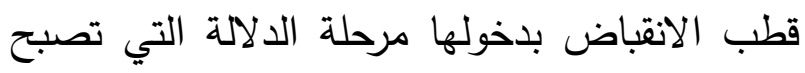
فيها ذاتا خائفة. تتشكل ذات الخوف في ديوان "ما لان تلاه عليَّ الغياب" في ثلاث صور : 
الخوف إلى دوامة الخوف من الغياب وانتظار الموت كحل لهذا الغياب. هناك ملمح مشترك بين الأهواء الثلاثة في الديوان، فهي تتصل بالغياب؛ الذي سبب حالة القلق التي

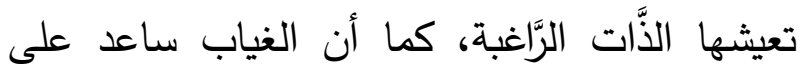
ضعف قيمة الأهواء الانشراحية المتمثلة في تحقيق قيمة الاستقرار للذات الرَّاغبة. المنظومة القيمية للأهواء في الخطاب الشعري التأسيس والاستعداد تبدأ هذه المرحلة مع بـع استعداد ذات الخطاب/الرَّاغبة لسلوك المسار الأهوائي، منتقية وبشكل مسبق عددًا من الأهواء دون آخر • ويبرز التأسيس في التشكيلات الأهوائية كصور تبرز بوصفها شروطًا مفترضة وتهيؤات قبلية، تحفز الذَّات التوترية على إنتاج الهوى تحت تأثير التوترات الموازية للانشطار • وهناك من جهة ثانية الاستيثاق الذي - استتادًا إليه - تتبثق القيمة، وغايتها توليد النظائر لاستقبال المرحلة التالية التي تصير فيها ذات هوى.' آ ولا يعني هذا أن دور التأسيس يقف عند افتتاح مسار الهوى، وإنما يرافق هذا الدور المسار الأهوائي طيلة أطواره. بَ تمهذ مرحلة التأسيس للاستعداد من خلال استدعاء محفزات، أو ما يسمى بالتوتر أو الاستهواء. وهذه المرحلة تسبق ظهور الهوى، فهي مرحلة إعداد الذَّات (كفاية الذَّات) للهوى. ففي هذا الطور، تتلقى الذَّات
يعيقها من تحقيق القيمة/الاستقرار، فنجدها في الخطاب الشعري باحثة عن هويتها، خائفة من

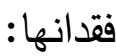
فعلا السكوتُ من أنتَ؟ قلتُ لصورة المرآةِ وعمّرت لحظاتي
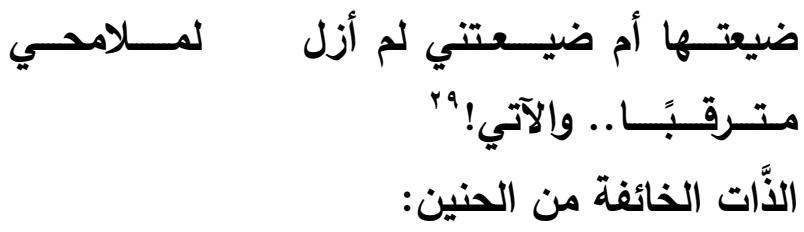
الحنين يمثل حضور مشاعر الشوق للذات الغائبة حين تتداعى ذكريات الذَّات المرغوبة الغائبة، فالذَّات الرَّاغبة تصبح في حالة انفصال عن الموضوع/لقاء الغائب؛ بسبب فعل الغياب، فالأشواق باقية ولا سبيل للخلاص منها، فالذَّات الرَّاغبة خائفة من توالي الأشواق وهي عاجزة عن التخلص من هذه المشاعر: كل أشواقي العاصفات توالت

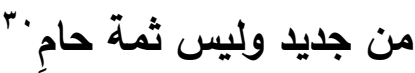
تكثف لنا تشكلات الهوى في ديوان "ما تلاه عليَّ الغياب" عن ذات راغبة في قيمة الاستقرار العاطفي من خلال اتصالها بموضوع الذَّات الغائبة، فهي قلقة وحيدة تعاني من علاقة إشكالية بكل شيء حولها: بالزمن وتحقيق الذَّات وغياب الأشخاص، فيسيطر على الديوان هوى الخوف والحنين واليأس، وإن نجحت في الانفلات من قبضة هوى اليأس في بعض القصائد، فإنها ما تلبث أن يأخذها هوى 
والكبت والتحفُظ؛ فجاءت الألوان الحيادية معادلة لإحساس الذَّات الشاعرة في ظل اختفاء الألوان التي

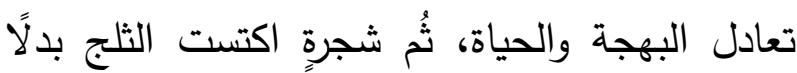
من أوراقها الخضراء على أرضٍٍ فلاة غيَّرتها رياح

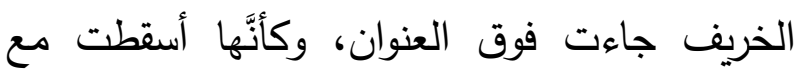
أوراقها ذكريات الماضي وصبَّتها على مخيَّة الشاعر، لتكتسي بياض الثلج ليّب ليغيب الشعور بالدفه، مولّدّةً الكثير من المعاني والتساؤلات في لُّاضي

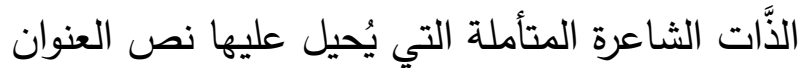
في مستواه (اللَّظي والدِّلالي والتركيبي). عتبة العنوان وظَّف الثاعر في العنوان ما (المصدريَّة) التي تختصُّ بالاقتران بالجملة الفعليَّة مع الفعل الماضي لمئي

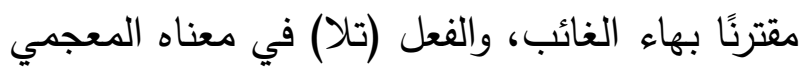

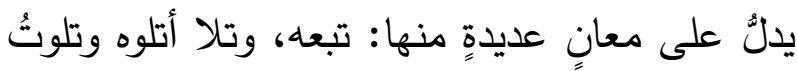
عنه، خذلته وتركته، وتلا عنبّي يتلو تلوًا: إذا تركلك وتخلَّف عنك، بلفظة الغياب بمعناها الجامد؛ ليُعبِّر عن حالةٍ وجوديَّةٍ يستقي منها حضورًا غائبًا لكلِّ

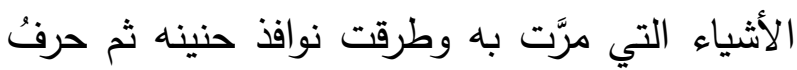

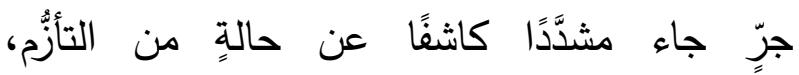
والذكريات التي فرضت نفر نفهاء عليه.

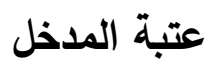
جاء مدخل الديوان ممثلًا لمرحلة التأسيس من خلال

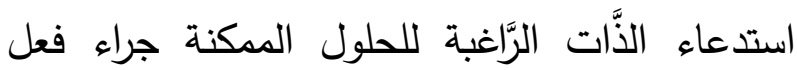

هب يلاحظ على قصائد الديوان كثرة ورود ملفوظ (الثتاء) حيث ورد في:

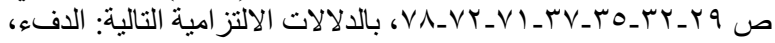

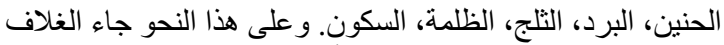
مؤسسًا لمضمون القصائد، خاصة، وأن فصل الثلى الثتاء يقترن عذادة جاء بالحنين.
الهَويَّة الجهية الضرورية من أجل تجريب هوى معين دون غيره؛ لذلك يُعد الاستعداد نوعا من الكفاءة التي

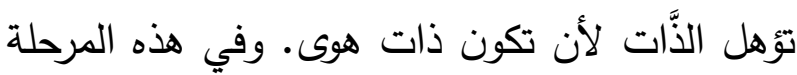
يبدو كل شيء جاهزا لانبثاق أثر المعنى الأهوائي

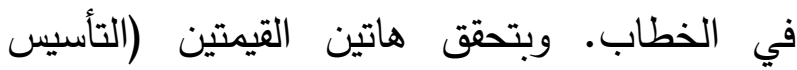

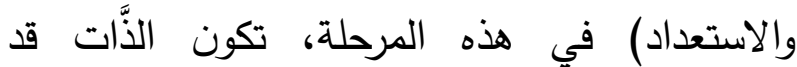

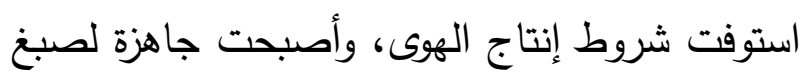
الخطاب بآثار المعنى الهوائي. وبالنظر إلى ديوان "ما تلاه عليَّ الغياب" نجد أن الن التأسيس بُني على فعل الغياب ابتداء من عتبات فلات الديوان، وهذا الغياب الذي تعاني منه الذَّات الرَّاغبة

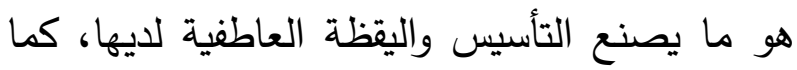
يصنع من الأَّات أرضًا قابلةً ومستعدة لإنتاج هوى لهئل الحزن بفعل الغياب. وهذا التأسيس تجلى في عتبات

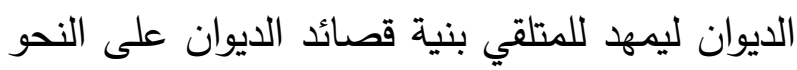

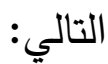

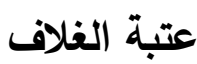
إذا تأمتلنا صفحة غلاف الديوان، تستوقفنا أمور عدَّة؛ فهو بثابة العتبات لنصوصه الداخليَّة؛ فالعنوان يشكّل حيزًا دون المتوسط بقليل على مستوى لئى

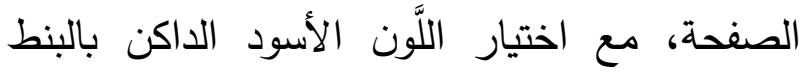
العريض، كما يُوحي السواد بالحزن العميق الموجود بداخل الشخص ويُخفيه عن الآخرين وسط خلفيَّةٍ رماديّةٍ جاءت محايدةً بين البياض والسواد بكلِّ ما لهذا اللَّون من دلالةٍ للسكون الذي يحفز للتأمل، فهو يخلق إحساسًا بالهدوء ويعفي من فوضى العالم 
وبفعل الإدراك لبقاء الذَّات الغائبة في الذاكرة، يدفع

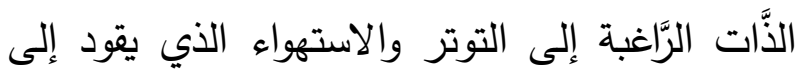

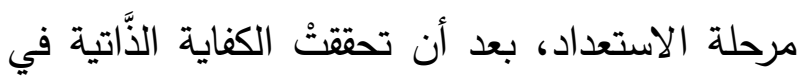

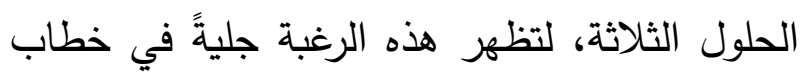
الذَّات الرَّاغبة في قصائد الديوان.

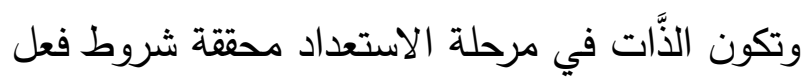
الهوى (ذات متوترة، وتوتير ، واستيثاق) Yr التي تؤهلها لأن تكون ذات هوى راغبة في مرحلة الاستعداد.

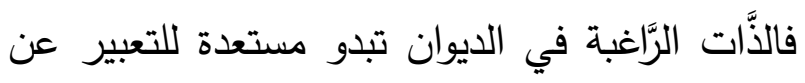

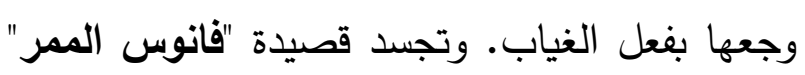
حالة انفصال الذَّات عن موضوعها مبتدئة ب: ونيا هذا الممر .. فانوسنا كم كان فيه يحتضر وأنا الوحيد بقربه ويداي باردتان تتلقطان ومض الموت فيه. ^״

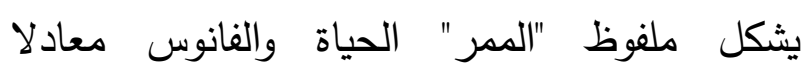
للمشاعر التي بين الذَّات الغائبة والذَّات الرَّاغبة،

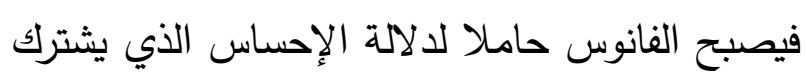

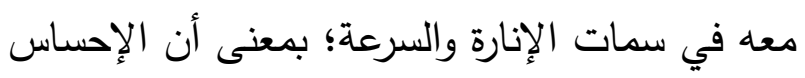
المقصود هنا ليس دائما ومستمرًا بل طارئ يمنح القدرة على الرؤية والكثف. تلتوالى لالأفعال

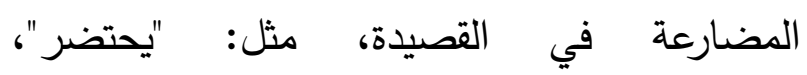

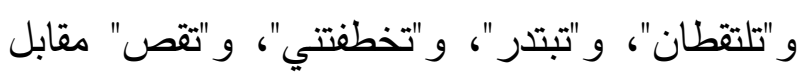

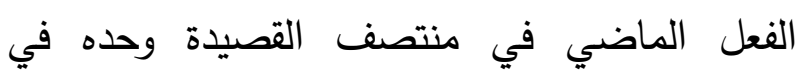

الغياب من الذَّات الغائبة، فتبدأ القصيدة مشكّلة حال

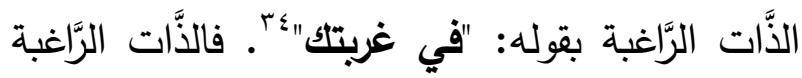
تدرك أسباب وجوهر ذلك الحزن، فهي تعيش حالة الانفصال عن الموضوع (المحبوب الذَّات الغائبة) غير محققة لقيمة (الاستقرار)، ويعبر عن هذه الحاله جملة: "في وحدتك" وجملة "في دمعتلك" من خلال

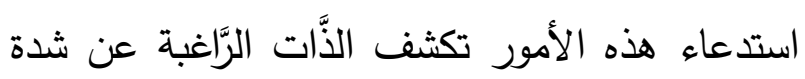
توترها وحزنها، فحزنها يتمثل في الغربة والوحدة

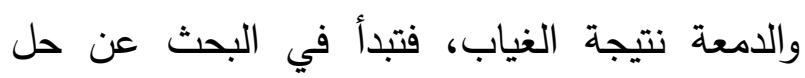
يكون مقاربًا لخلجاتها، قريبًا من معاناتها، فلم تجد أنسب من ثلاثة حلول مقترحة مرتبة في القصيدة على النحو التالي: هن تلاته هو وحده قاع الثعور يطيق أن يتنفسكُ هي وحدها تلك القصيدة من تطيق تلبُّكُّ؛

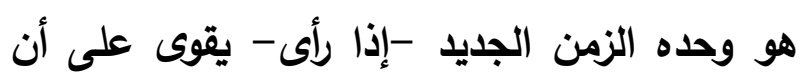
يؤْنسك! هو وحه ويكون الخلاص للذات من خلان ثلاثة أمور: الشعور بالذَّات، والقصيدة (الكتابة)، والزمن الجديد

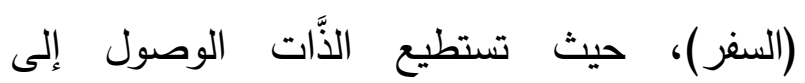
القيمة/الهدف بهذه الحلول، ولكن تدرك الذَّات الرَّاغبة أن ذللك محال بسبب الذكريات التي لا تفارقها: من ذا أعادك يا بعيد

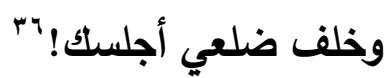


السطر "غبت". وكل ملفوظ من الأفعال المضارعة فإذا فهت بعدها كان حرفي

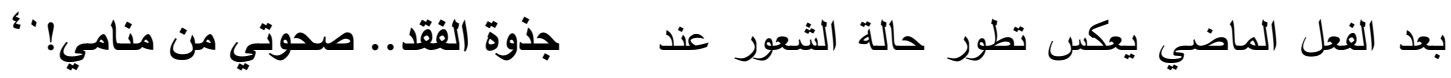

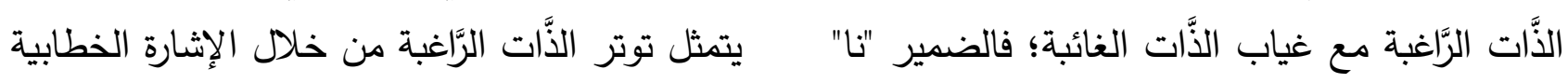

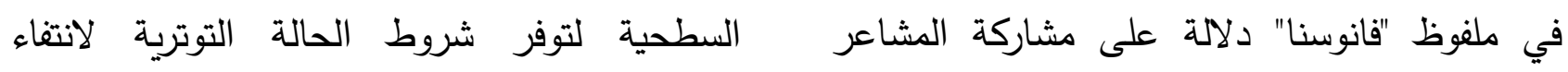

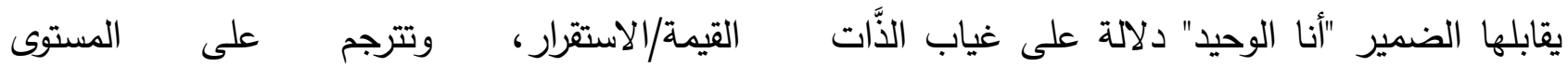
الإبستيمولوجي بـ"انغلاق" توتري أولي، يسمح بسيطرة الغائبة.

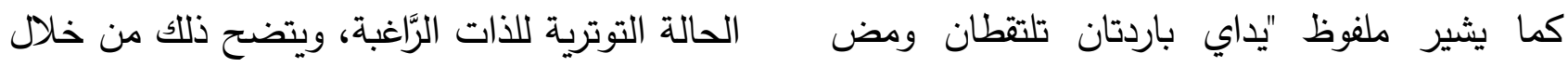
الموت فيه" إلى محاولة الذًات الرَّاغبة في بقاء

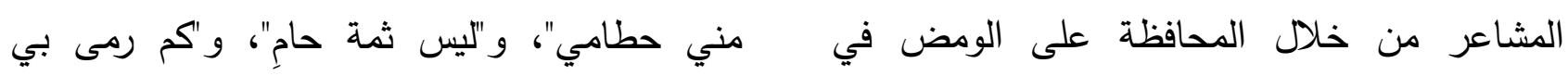
الفانوس من الموت، ولكن هناك عوامل تعيق الخيال صوب جنونٍ".

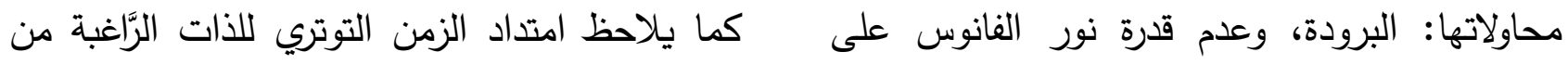

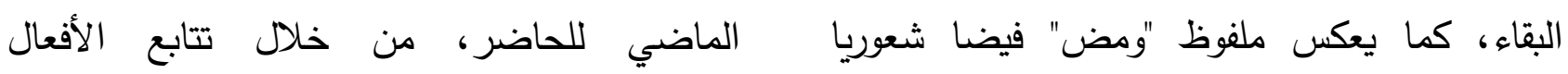

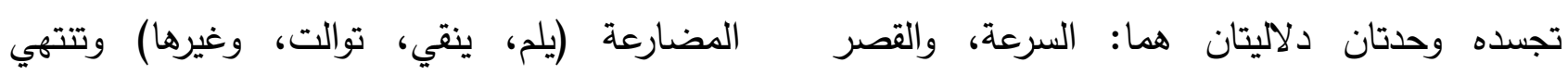

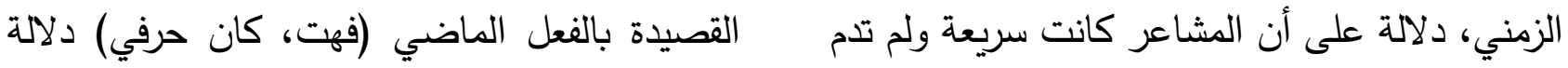

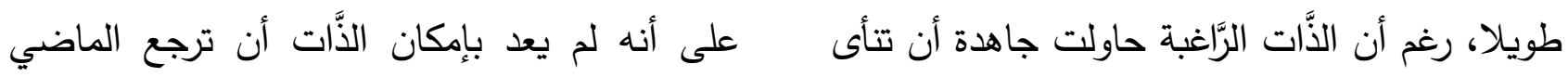

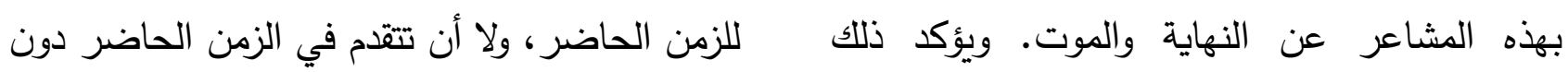

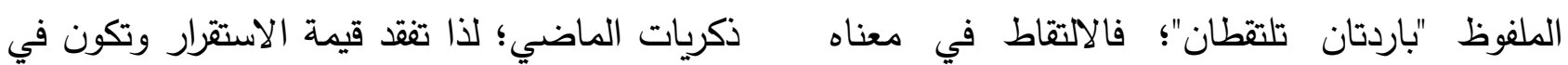

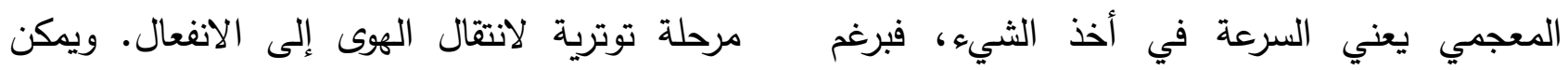

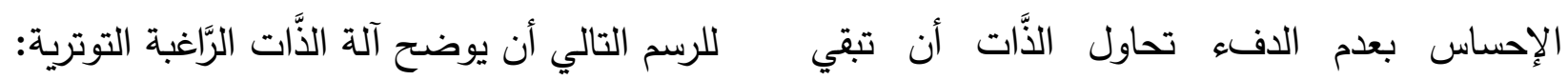

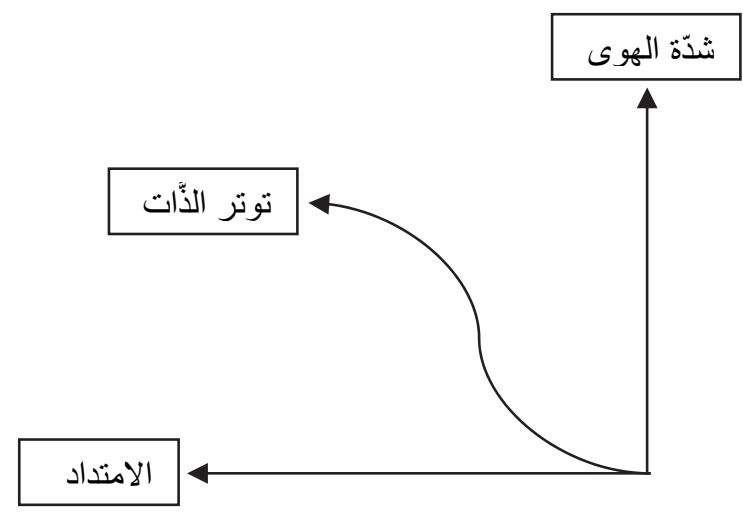
الفانوس مشتعلا.

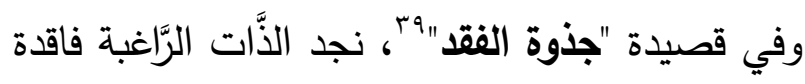

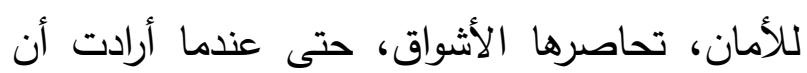

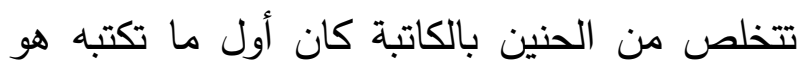

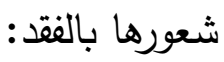




\section{ولكن قال كل الثيء بـ}

تحاول الذَّات الرَّاغبة الاتصاء لباء بالموضوع وتحقيق

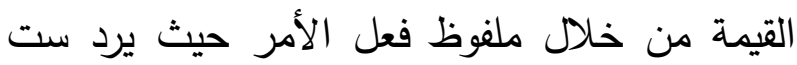
مرات في القصيدة: "اقرئي"، "اكتبي"، "حبري"، "أسدلي"، "اتركي"، " أخبري"، وفي كل أمر من الذَّات

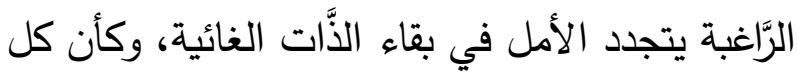

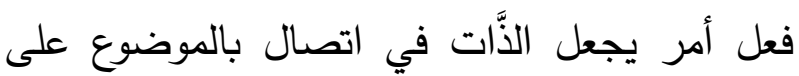

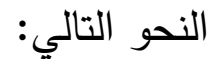

تجعل من نفسها الليل وتطلب من الذَّات الغائبة

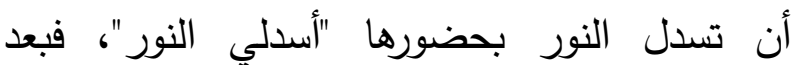
الظلام حتما سيكون النور

تطلب الذَّات الرَّاغبة من الذَّات الغائبة إذا تعذر

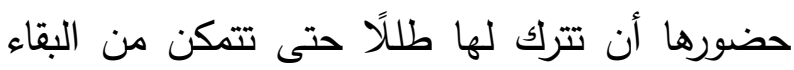
"اتركي لي طلال". تجعل الذَّات الرَّاغبة الخلاص في إجابة الذَّات الغائبة، لأن أسئلتها تتبع من شعور صادق لرافيه لا يشوبه

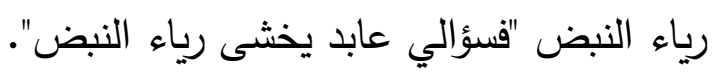

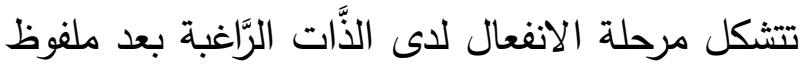

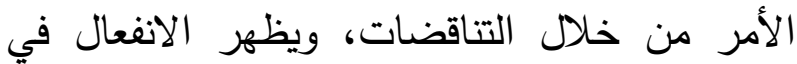
ذروته في التتاقض: لم يقل/قال، هديل الموج/قاع الاعن التعال

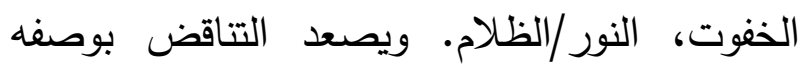
هوى انقباضيا، حيث يقابل الحالة الشعورية عند الذَّات الرَّاغبة بين المد والجزر والأمل واليأس من النّان

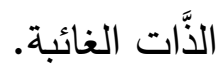

\section{التحسيس والانفعال}

تتحول التوترات في مرحلة التأسيس إلى هوى، وبعد

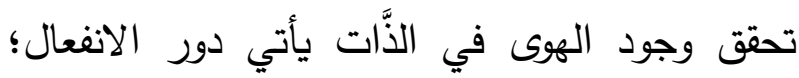

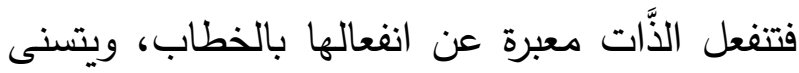
لها التعرف على الاضطرابات الغامضة التي جربتها في الطورين السابقين؛ حيث يتم ضبطها في إطار هوى محدد. ويتجلى التحسيس من خلال التكثيف بضل معجمة الآثار المعنوية، ويمكن التعرف عليه

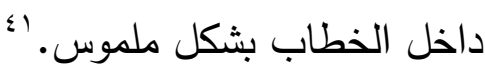

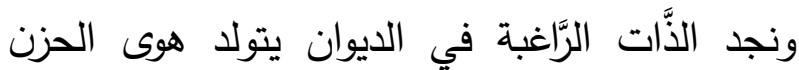
لايها بفعل الغياب من خلال التتاقضات الداخلية، حيث إن التلاحم الجهي يحدث شقًا داخليًا في الذَّات سببه وعي الاستحالة الذي يطبعه هوى اليأس.

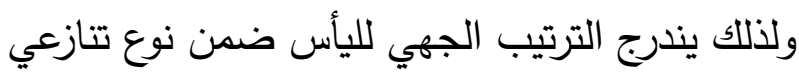

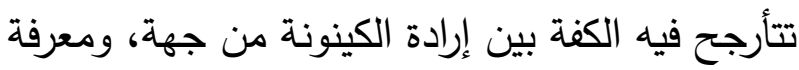

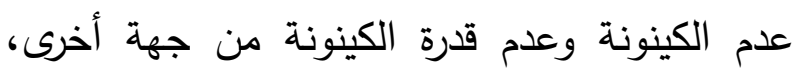
دون أن ترجح كفة أحد الطرفين على أحد.

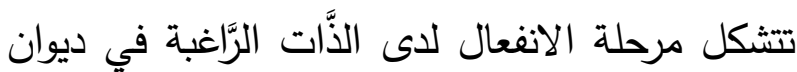
"ما تلاه عليَّ الغياب" من خلال التناقضات، يتجلى ذللك في قصيدة "رياء النبض" فنجد الذَّات الرَّاغبة في مواجهة مع الذَّات الغائبة من خلاد محاورتهاء اقرئي سطرًا تناهى أوله

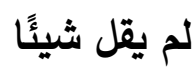


وفي ظل هذا الضياع، تبحث الذَّات عن مأمن

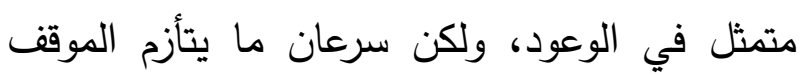

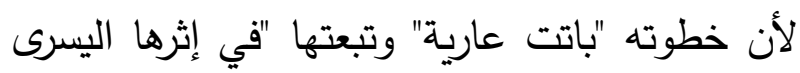

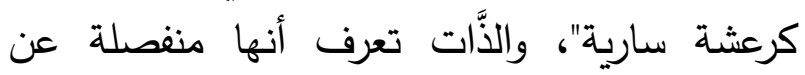
موضوعها، فبين عدم قدرة الكينونة وبين إرادة

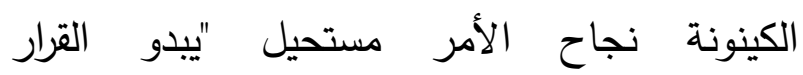
كمستحيل"، حيث تبقى الذَّات مصرة على الاتصال بالموضوع رغم يقينها بالفشل، متسائلة: "كيف لي أن أن النيات أستمد من الغموض قراريهة. وتعيش الذَّات الرَّاغبة الانفعال من خلال التناقضات

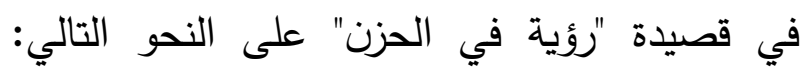

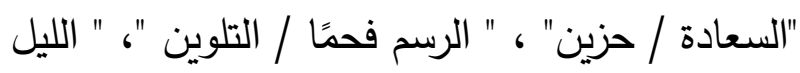

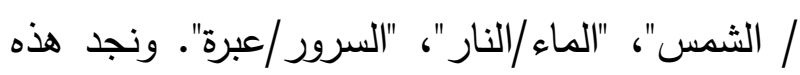

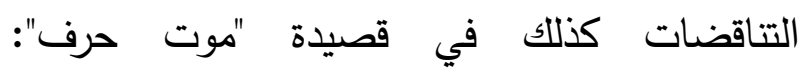

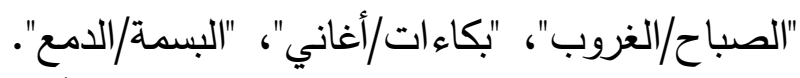

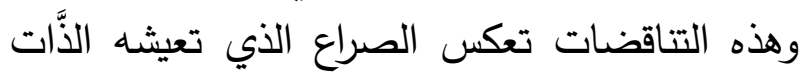
الرَّاغبة من أجل تحقيق قيمة الاستقرار • ويمكن للرسم

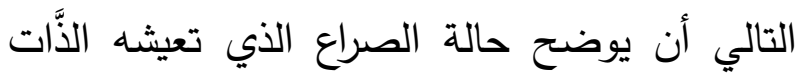
الرَّاغبة حيث يكون الهوى في صعود إلى الأعلى:

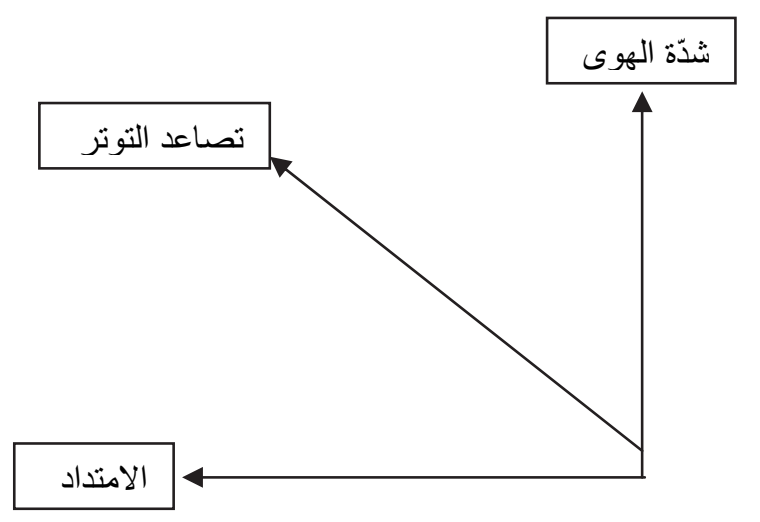

كما يظهر التقابل بين خاتمة القصيدة "فيؤالي عابد

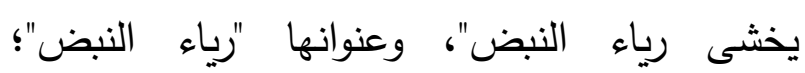

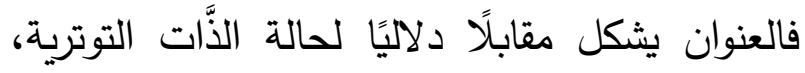

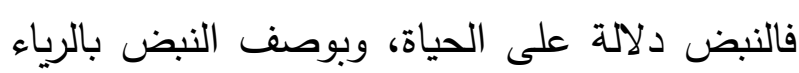
يؤكد بأن الذَّات لا تشعر بالحياة. وفي قصيدة "عراء!"، يسيطر على لألى الذَّات الرَّاغبة

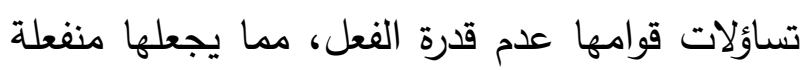
تبحث عن سبب الشعور بالضياع، فنشأ هوى اليأس في الخطاب على شكل توتر بسبب غياب الماضي (الذكريات)، وهذا الغياب يخلق صدعا في في أفق لترن

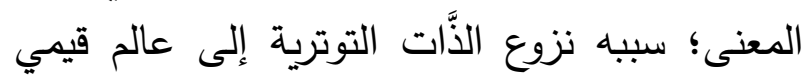
مغيب، يهدف إلى تحقيق الاكتمال وسط حضور معنن في الخيبة. فتبدأ القصيدة بتساؤل الذَّات الرَّاغبة: أنأنا أسير أنة: أم الحياة السارية؟

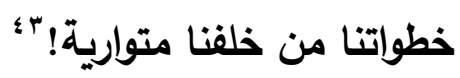
تتثكل الصيرورة التوترية من خلال الهوى التوتري منواريها

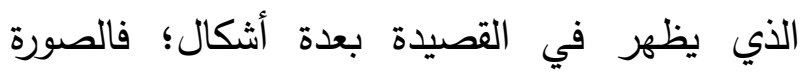

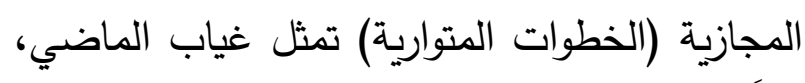

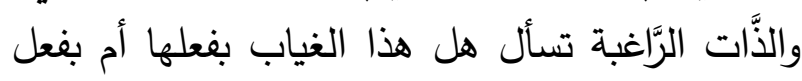

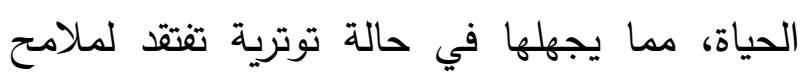

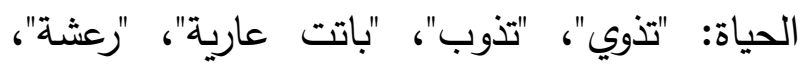
فتحاول جاهدة أن تحقق القيمة (الاستقرار): وأقدم اليمنى.. لتحتضن مأمنًا بالأمس واعدها

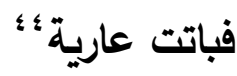


القصيدة بانفصال الذَّات الرَّاغبة عن الموضوع،

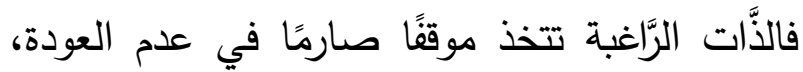

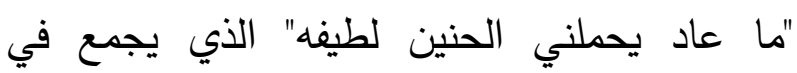
مفارقة أسلوبية بين الذَّات الرَّاغبة "يحملني" وياء

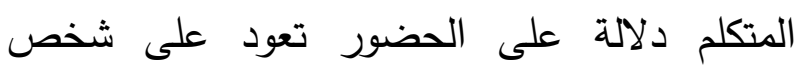

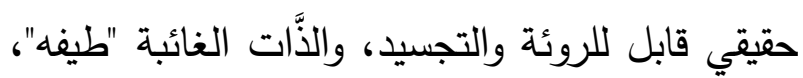

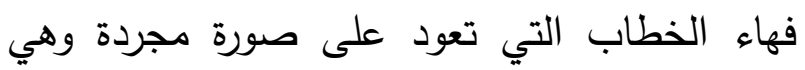
الطيف دلالة على الغياب، مما يجعل تفريعات لفهات

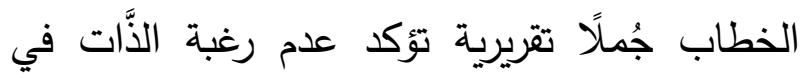
العودة على هذه الثاكلة: ما أبعد الارب الأي واريتُّهُ قلبي القريب ولا تسل عن كيفه لغة المجاز مجازر باركتها

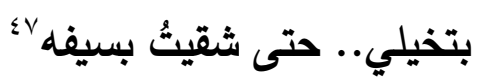
يعكس المقطع السابق انقطاع السبيل لعودة الذَّات الرَّاغبة، فانقطاع الأمل ينجم عن وجوب الكينونة،

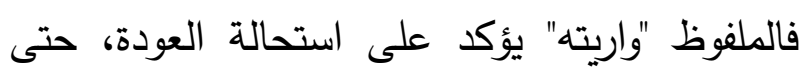
وإن كان القلب بما يحمله من حنين قريب، فالذَّات الرَّاغبة لا ترغب حتى في سؤال الذَّات الغائبة عنه.

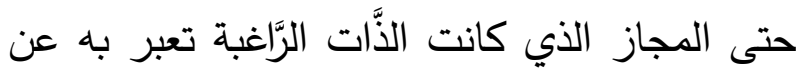
مشاعرها أصبحت "مجازر باركتها" وتاء المتكلم دلالة عى تأكيد فعل الكينونة من الذَّات الرَّاغبة، لأنها كل ما كانت تعبر عنه من أجل تحقيق ذاتها
التهذيب

يختتم المسار الأهوائي بحكم أخلاقي سلبي أو إيجابي على ما تجلى من الأهواء بعد الانفعال، وهي لإي لئي

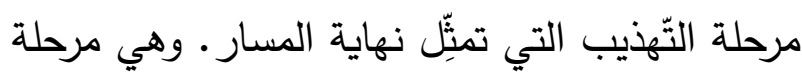
تأتي بعد مرحلة ظهور الهوى في الخطاب؛ فيصبح الهوى قابلًا للملاحظة والقياس، وهذا ما ما يكسبها

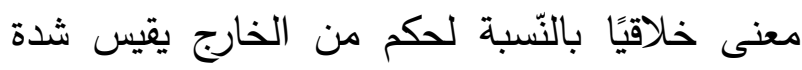
الهوى وضعفه ونظرة الذَّات والمجتمع إليه، ويدرج

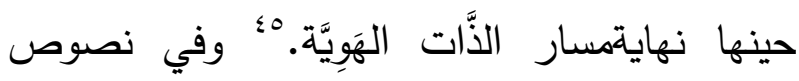
الدراسة، يمكن قياس أثر الغياب في حالين مختلفين: سلبي وإيجابي. أولا التهذيب الإيجابي ولي تسعى الذَّات الرَّاغبة في التهذيب الإيجابي إلى إيجاد الحلول للتخلص من الحزن بفعل الغياب؛ لتحقق القيمة/الاستقرار العاطفي. ولا يكون ذلك إلا من

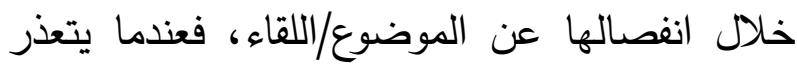
الاتصال بالموضوع، تتحقق القيمة/الاستقرار بيقين الذَّات أن خلاصها في "الزمن الجديد" بـأ الذي تعيشه بدون حنين وذكريات الماضي. ففي قصيدة "عبء المجاز"، تصل الذَّات إلى حكم

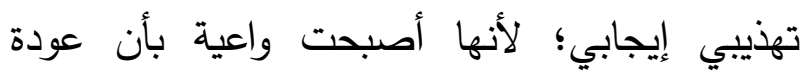
الذَّات الغائبة مستحيلة، فحين تعيش في الذكريات لاتئات

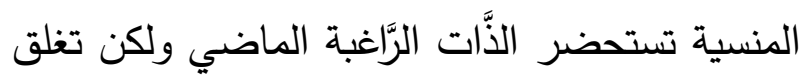
دونه كل سبل التسرب إلى زمنيتها الخاصة؛ فتبدأ 


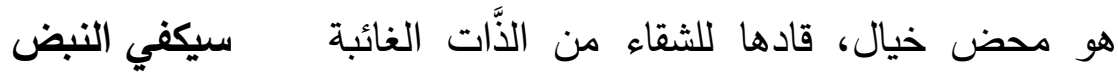

ويُيسع خلف ضلوع اللحظةِ بين زفير حنَّ

وبين خيال شهيق! 9 ؛

تكثف الصورة الشعرية عن حالة وجودية/التنفس، ترغب بها الذَّات كملجأ لتحقيق هدفها، حيث جاء الزفير معادلا للتخلص من الحنين، يقابله الثهيق

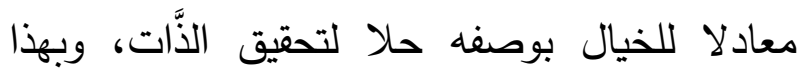

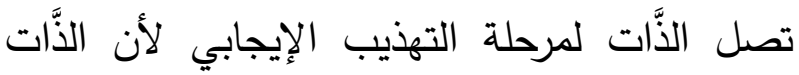

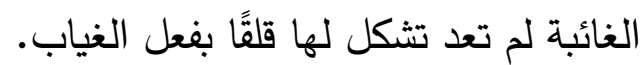
ويتكرر هذا الحل الإيجابي في قصيدة "على ضفة لهل أمنية" وقصيدة "لهفة الأرض!"، حيث تكون الذَّات الرَّاغبة على يقين بأن الماضي تستحيل عودته، وفي قصيدة "حديث إلى الشعر" لم تعد الذَّات الرَّاغبة تعبأ بعودة الذَّات الغائبة، حيث تخاطب الثِّن الثِعر قائلة: الآن هل أحد سوانا أهرق الحرف الذي شنق التعاويذ القديمة

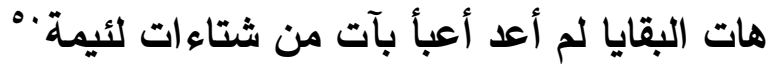
ثم تخبر الشعر بأنها لن تبوح بالثكوى بعد ذلك الكاء

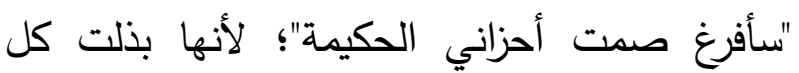
الحلول الممكنة للتخلص من ذكرى الذَّات الغائبة

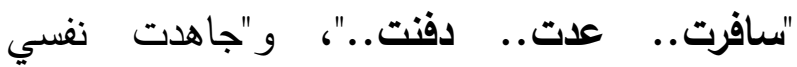

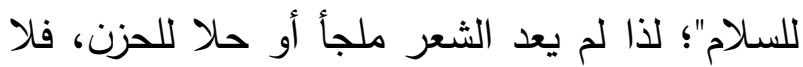
تبالي بجودته فتخاطبه قائلة: "كن ركيكا ليس لؤمك

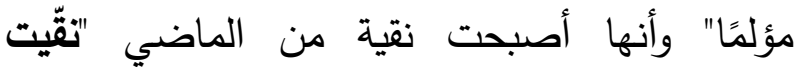

التي قطعت كل السبل بينهما. وفي نهاية القصيدة يتأكد انفصال الأَّات الرَّاغبة عن بن

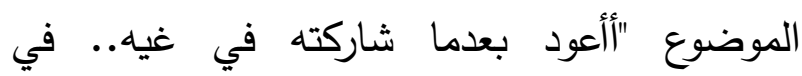
حيفه؟!" يشكل ضمير المتكلم الغائب أنا في الملفوظ فئر فئه "أأعود" تأكيدًا في عدم الرغبة في العودة، واقتران ضمير المتكلم التاء مع ضمير الغائب الهاء في

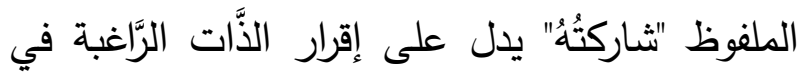

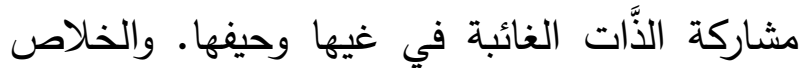
يكون في عدم العودة وبدء حياة جديدة. وفي قصيدة "صوب الصامتين" ترى الذَّات الخلاص من حالة الحزن عن طريق الصمت مشكلا تهذيبا

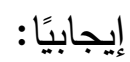

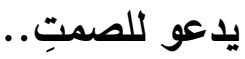

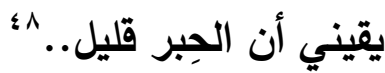
نجد أن ملفوظ "يقيني" يمثل وصول الذَّات الرَّاغبة لمرحلة اليقين، وهذا دلالة على اعتقاد راسخ وثقة تامَّة بالحل الذي وصلت له بأنه لا تراجع فيه، وهذا

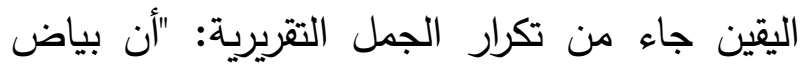
الصفحة سوف يضيق"، و"أن الصوت يُبحُّ.."، و"أن

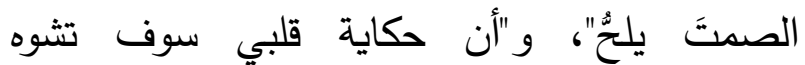
بالأصوات"، وكل الصور الشعرية تؤكد هذا اليقين.

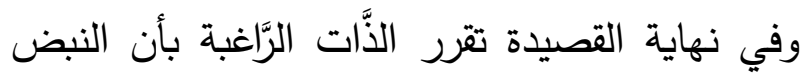

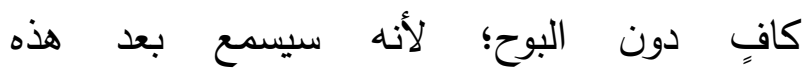
اللحظة/القرار : - الحرن 


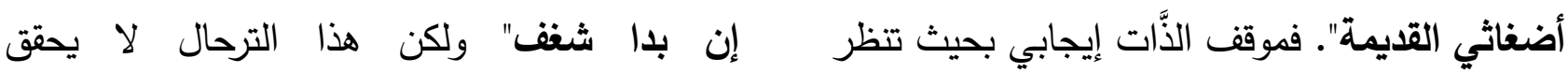

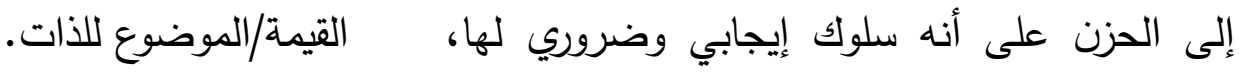

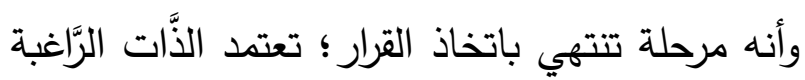
إلى التأقلم مع الحزن أو الغياب وموقفها هذا مهيمن وفي قصيدة "من حديث الرابية"، تجد الذَّات الرَّاغبة في السفر ملجأ للحنين الذي تشعر به: "أنتوق لرابث

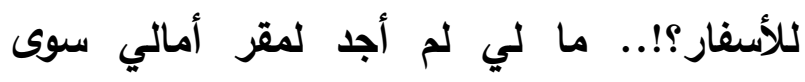
ترحالي!"، وكذلك في قصيدة "الفراغ الرحب" نجد الذَّات الرَّاغبة في الدوامة ذاتها: قلبي حقيتي التي لم تعترف يوما بوعثاء السفر كم داوم الترحال..

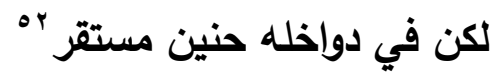
تحضر الذَّات الرَّاغبة في بداية القصيدة بشكل غير فئر

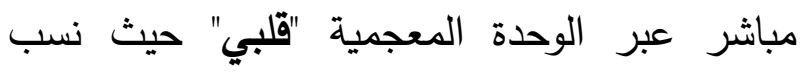
القلب إلى "أنا" المتلفظ عبر الياء باعتبار القلب مصدر الشعور والإحساس، ويظهر القلب/الذَّات كعامل مستقل يملك إرادة الفعل، فالذَّات في سبيل ولإلي

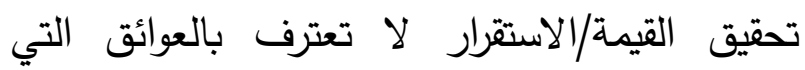

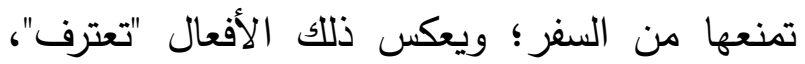
و "يسري"، و "يقاد" وكلها أفعال مناسبة لفاعلها القلب. وفي نهاية القصيدة، يتضح سبب الدوامة التي تعيشها الذَّات من خلال موقف القلب/الذَّات حيث أصبح منقادًا لهذه الفكرة لأنه لا يستجيب للعقل: ما صار يفقه ما أقول.. وصرت أتبع ما يغنّي.. "ror. ثانيًا التهذيب السلبي تضع الذَّات الرَّاغبة حلوًا للتخلص من الحزن بفعل

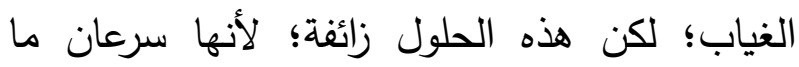

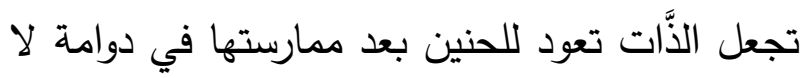
تنتهي، مما يجعلها في حالة انفصال عن القيمة الأساسية/الاستقرار ، حيث تبدأ بعد وضع الحلول في دوامة الأسئلة والتناقضات. ففي قصيدة "حداء مسافر" تظهر محاولة الذَّات الرَّاغبة أن يكون الماضي حاضرا في واقعها رغم قسوته، حتى تحقق القيمة/الاستقرار : في رحلتي يتجدد السفرُ!

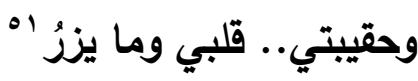
تتخذ الذَّات السفر ملجأ لها من واقعها المؤلم، رغم الطريق الوعر وما يحمله القلب من وجع ثقيل، من ولهات فالذَّات الرَّاغبة مرتبطة بالسفر بيؤكد ذلك تكرار

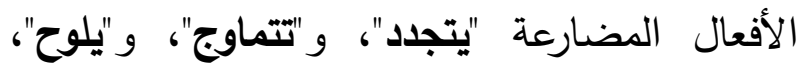

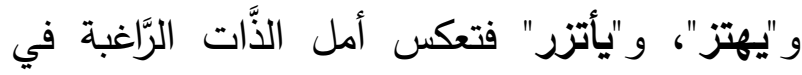
استمرار الحالة الشعورية التي تعتقد بإمكانية تحققها عبر السفر ، فهي دائما مستعدة للترحال 'كلي ارتحال 
وفي المقطع الثالث تتكر الذَّات قدرة القصيدة/الكتابة على التخلص من الحنين "هل يريح الصمت أشلاء الحجر". 0. ويؤكد المقطع الرابع عدم قدرة الذَّات على الثعور لقنا لكنائها: ما الجزء مني قد تبقى للزمن؟ ما الكل مني قد تحفز للوطن؟

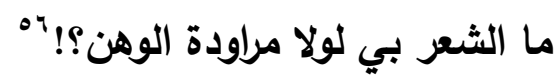
جاءت هذه الأسئلة المفتوحة لتضع نهاية مفتوحة؛ ماودة التهن

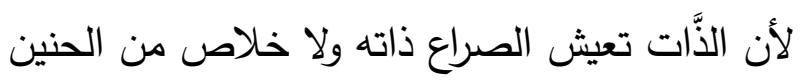
جراء فعل الغياب، فقد بُبئت الحلول الثلاثة في مدخل الديوان بالشعور بالذَّات، ثم القصيدة ثم الزمن الجديد. وأما في قصيدة "فتيل الأسئلة"، فتبدأ بإنكار مدى جدوى هذه الحلول مبتدئة بطريقة عكسية على الجى

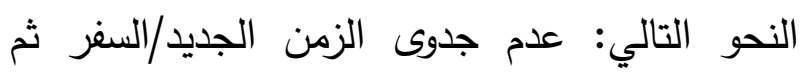
القصيدة/الكتابة، ثم عدم مقدرة الذَّات على تحقيق قيمتها ليجعل الذَّات منفصلة عن القيمة/الاستقرار من بداية الديوان حتى نهايته. ويأتي عنوان القصيدة

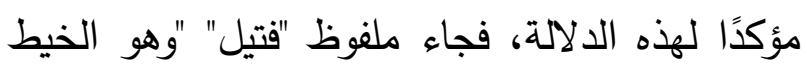
سريع الاشتعال يوصّل بالمتفجّرات ليفجّرها إذا إذا لهاء

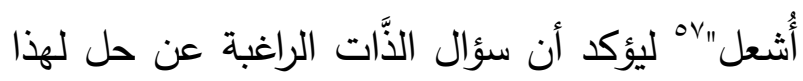
الغياب يسبب اشتعالا في مشاعرها واستقرارها. لأنها
فالتهذيب هنا سلبي لأن الذَّات لم تتخذ موقفًا حيال

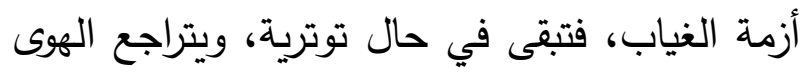

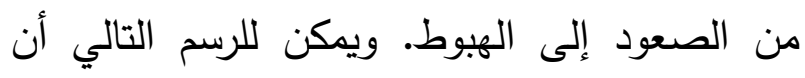
يوضح حالة الهوى عند الهبوط:

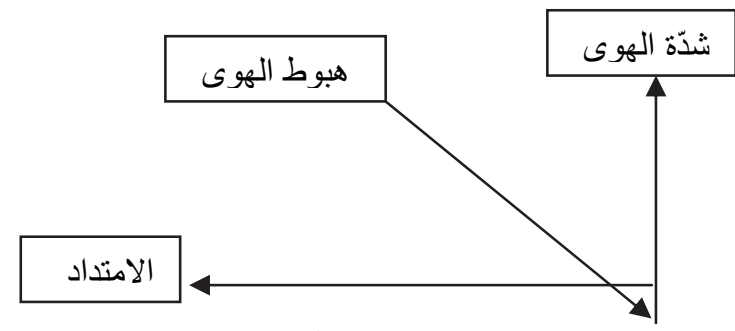

هناك ملمح مشترك بين الأهواء في المراحل السابقة، فهي تتصل بالغياب الذي سبب حالة القلق التي لالتي

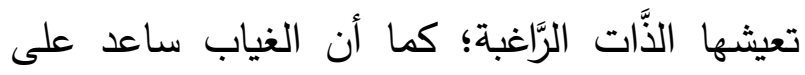

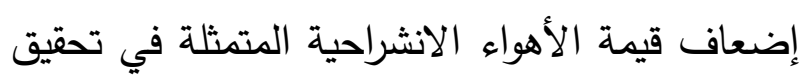
قيمة الاستقرار للذات الرَّاغبة، ويؤكد ذلك القصيدة التهاه

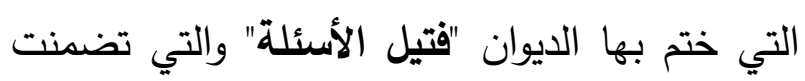
مجموعة من الافتراضات والأسئلة الإنكارية لبيان مدى جدوى الحلول التي وضعتها الذَّات في مدخل الأكرنة الديوان. احتوت القصيدة على أربعة مقاطع على النحو

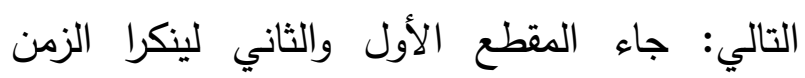
الجديد/السفر بوصفه حلا: لو كان ذلتك.. كله أو بعضه كان دل لانزاحت الأسفار عن كتف السنين

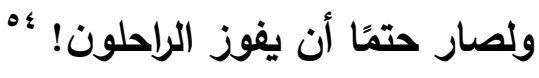


الربيع الممتلئ بالدفء، ثم يعبه شتاء، وهكذا

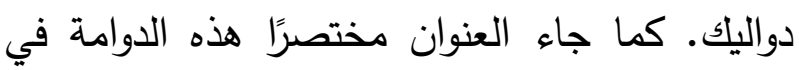
جملة واحدة "ما تلاه عليَّ الغياب" مؤكدا أن سبب لهون

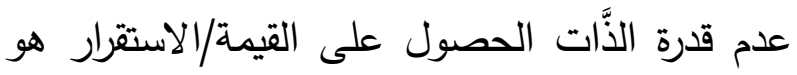

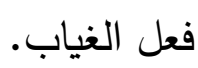

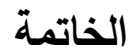

حاول البحث الكثف عن الأهواء التي تشكل منها ديوان "ما تلاه عليَّ الغياب" واكتشاف مدى تأثيرها على تشكيل الدلالات المختلفة. جاءت سيمياء الأهواء من السيمياء السردية، لهاءل معتمدة على الفضاء العاطفي الذي يخضع لمراحل

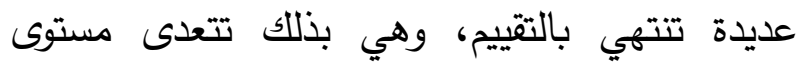
الفعل لتصل في النهاية إلى دور الأهواء في توليد الدلالات في الخطاب الشعري والعمل على تحريكها. نظرا لأن الخطاب الشعري خطاب وجداني عاطفي، فإن الأهواء تحتل فيه حيزا كبيرا، وهذا ما يجعله مجالا مناسبا لتطبيق سيمياءات الأهواء التي لتهبراء لم تحظ بحقها من التطبيق في النصوص الإبداعية، وقد كثف البحث عن نجاح إجراءاتها في الوصول إلى دلالات لا يمكن كثفها لو وظف البحث مناهج

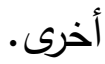

لعب الغياب دورًا هامًا في الديوان من خلال إبراز الحالات الانفعالية للذات، ابتداء من العتبات

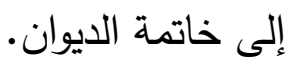
كثف التحليل عن ثلاثة أهواء تشكلت من خلالها قصائد الديوان وهي: الحنين، واليأس، والخوف.
في حالة بحث دائمة عن الحل المستحيل، ويمكن للشكل التالي أن يوضح سبب الدوامة التي تعيش

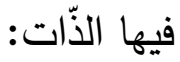

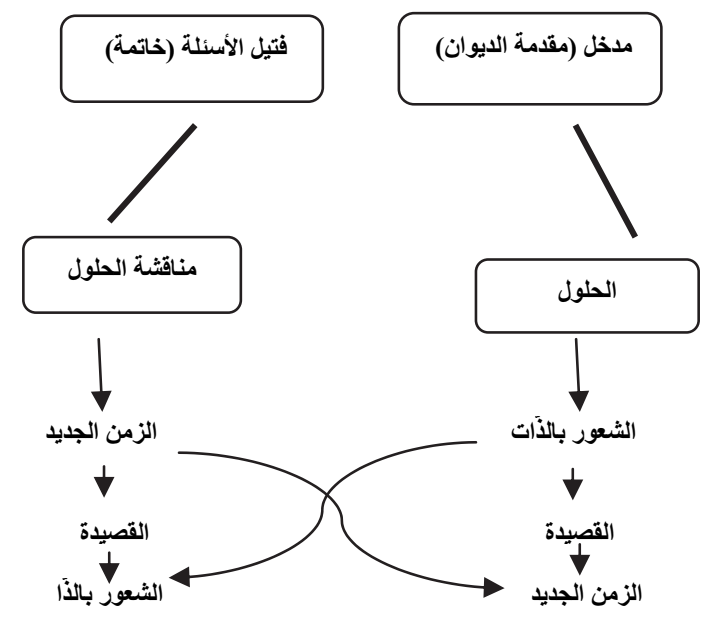

يكثف الرسم السابق عن دوامة البحث عن الذَّات

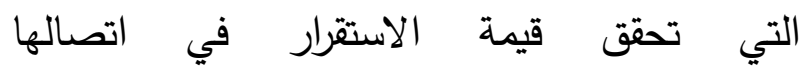

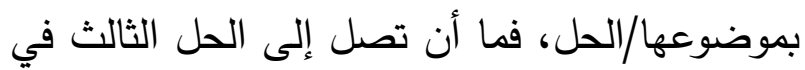
مدخل الديوان (الزمن الجديد) حتى تعود إلى إثارة

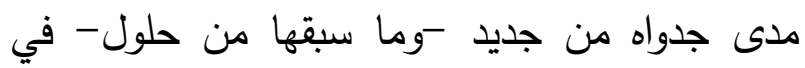

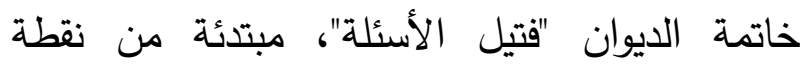
النهاية في الحلول؛ لتعلن أن هذه النهاية ليست حلا

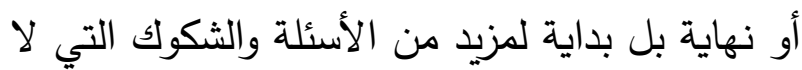

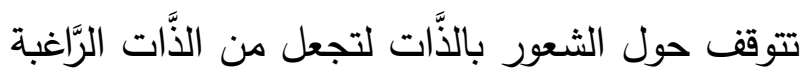

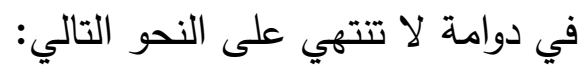

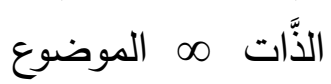
ودوامة البحث عن الذَّات التي كثف عنها التقابل بين مدخل الديوان وخاتمته، جاء غلاف الديوان مؤسسًا لها؛ فالشتاء الذي يغيب فيه الدفء يعقبه 
قائمة المصادر والمراجع

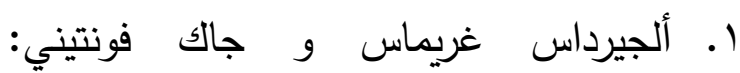
سيميائيات الأهواء من حالات الأشياء إلى حالات

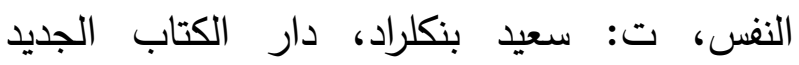

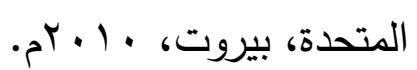

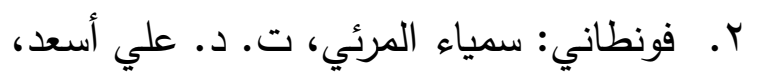

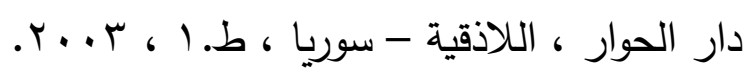

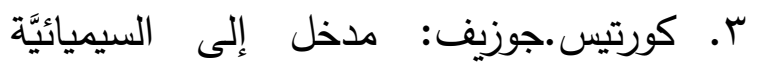

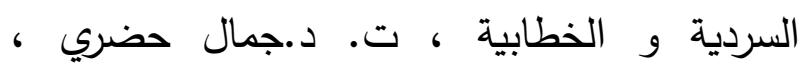

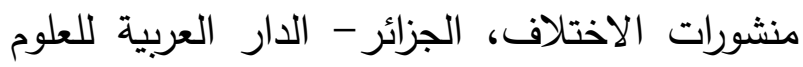

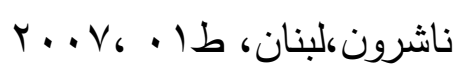

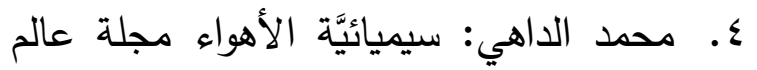

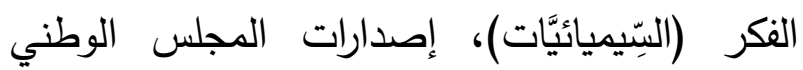

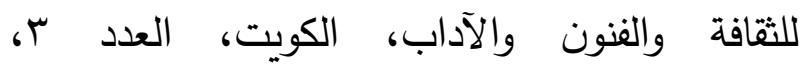

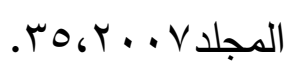

ه. محمد بن مكرم بن على، أبو الفضل، جمال

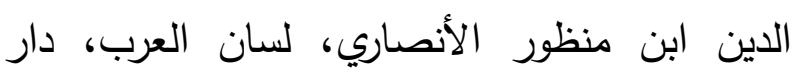

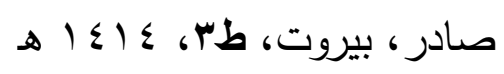

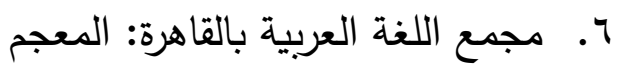

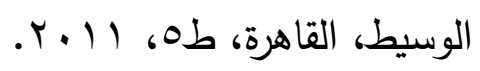

\section{المراجع الأجنبية}

1. Greimas et Jacques Fontanille:

2. Sémiotique des
اختلاف الأساليب الثعرية في مراحل المنظومة القيمية للأهواء في الايوان على النحو التالي:

في مرحلة التأسيس والاستعداد، كثر الاستفهام التقريري والصور المجازية. في مرحلة التحسيس والانفعال، نجد أنها تشكلت من التناقضات والأسئلة الحقيقة.

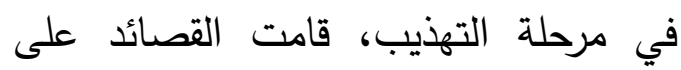
الجمل التقريرية المؤكدة. •ليس هناك اتصال فعلي أو انفصال فعلي بين الذَّات وموضوعها، ويتضح ذلك في أن الذَّات

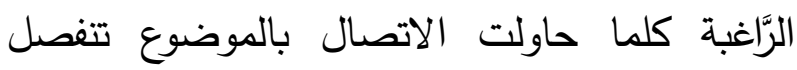

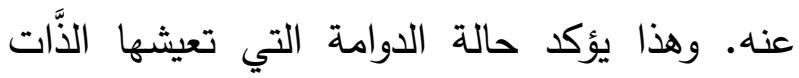
الرّاغبة، فالغياب فعل لا يمكن أن ينتهي. الذَّات الرَّاغبة في الديوان متأملة، كما أن لنان لغان

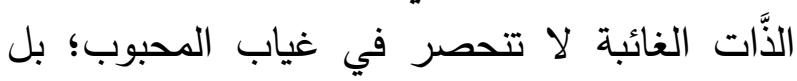
شملت غياب الأم والأب والمشاعر والأماكن والزمن في لابت بلت

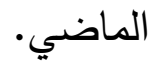

3. passions.SEUIL.PARIS.France.1991

4. Courtés.J , Analyse sémiotique du discours; de l'énoncé a l'énonciation, Hachette , Paris , 1991 


\title{
The Semiotics of Absence in Ma Tlahu a'li Alghyab (what absence has told me): a study in the shade of the semiotics of desires

\author{
Dr.Alreem M Alfawaz
}

\begin{abstract}
T he semiotic approach is based on the assumption that the text includes a surface structure and a deep structure. Analyzing the two structures looks at the relations between the two. As for the objective behind the semiotic approach it is the uncovering of the relations that link the hidden implications of the text by following the development of meaning. On the other hand, the semiotics of emotions is a branch of general semiotics. Emotion is what semiotics analyzes to know its role in the creative text. In the collection of poems discussed here it is absence that played a role in the formation of the emotion of sadness :the absence of people or specific attitudes. Sadness is seen as preceding the ways meaning reveals itself and also as an agent in their production.
\end{abstract}

Key words are :the semiotics of emotions, sadness, absence. 